\title{
LAS TENSAS RELACIONES ENTRE EL TRIBUNAL SUPREMO Y EL TRIBUNAL CONSTITUCIONAL $Y$ LOS LÍMITES DE LA (LEGÍTIMA) DISCREPANCIA ENTRE ELLOS
}

FRANCISCO JAVIER MATIA PORTILLA 
SUMARIO

1. ALGUNAS CONSIDERACIONES PREVIAS SOBRE LA JURISPRUDENCIA CONSTITUCIONAL Y SU CRÍTICA. 2. LOS COMPORTAMIENTOS DISCUTIBLES: 2.1 Los Tribunales deben expresarse a través de resoluciones; 2.2 Los Tribunales deben respetar la doctrina constitucional; 2.3 Un Tribunal no puede controlar la actuación jurisdiccional de los Magistrados del Tribunal Constitucional. 3. ALGUNAS CONSIDERACIONES CONCLUSIVAS. 


\title{
LAS TENSAS RELACIONES ENTRE EL TRIBUNAL SUPREMO Y EL TRIBUNAL CONSTITUCIONAL ${ }^{1}$ Y LOS LÍMITES DE LA (LEGÍTIMA) DISCREPANCIA ENTRE ELLOS
}

\author{
FRANCISCO JAVIER MATIA PORTILLA ${ }^{2}$ \\ Catedrático de Derecho Constitucional
}

\section{ALGUNAS CONSIDERACIONES PREVIAS SOBRE LA JURISPRUDENCIA CONSTITUCIONAL Y SU CRÍTICA}

Resulta indiscutible que el Tribunal Constitucional tiene un gran poder, ya que es el encargado de controlar la actuación normativa de los parlamentos que encauzan, a diario, el principio democrático. Y además sus decisiones no pueden

${ }^{1}$ El profesor Aguado Renedo hace notar acertadamente que, en realidad, las malas relaciones no han sido bidireccionales, sino que, en el ámbito civil, han sido fundamentalmente protagonizadas por la Sala de lo Civil del Tribunal Supremo (en «Del intento de control del Tribunal Constitucional por la Sala de lo Civil del Tribunal Supremo o de cómo poner en riesgo todo un sistema». Revista General de Derecho Constitucional 1, 2006, p. 8). La primera monografía dedicada a esta cuestión en nuestro país es la de Rosario Serra Cristóbal, La guerra de las Cortes: la revisión de la jurisprudencia del Tribunal Supremo a través del recurso de amparo (Tecnos. Madrid, 1999). Ver, también, Hansen, Cornelia: Guerra de Cortes - Der Konflikt zwischen dem Spanischen Verfassungsgericht und dem Spanischen Obersten Gericht. Verlag Dr. Kovac. Hamburgo, 2008 y Mendizábal Allende, Rafael: La guerra de los jueces. Tribunal Supremo vs. Tribunal Constitucional. Dykinson. Madrid, 2012.

${ }^{2}$ F. Javier Matia Portilla. Departamento de Derecho Constitucional. Facultad de Derecho. Universidad de Valladolid. Pl. de la Universidad, s/n. 47002 Valladolid. Email: javierfacultad@ gmail.com 
ser revisadas por ningún otro Tribunal ni nacional ni extranjero. No resulta extraño, entonces, que deba administrar su esencial cometido para el mantenimiento del Estado constitucional con especial cuidado y prudencia. Esta prudencia debe canalizarse a través de una cuidada y detallada fundamentación que permita comprender sus decisiones.

De esta forma, resulta preciso señalar de entrada lo obvio: las resoluciones del Tribunal Constitucional gozan de una autoridad que debe ser respetada por todos: por todos los órganos del poder público pero también por los ciudadanos (que están vinculados por la Constitución ex artículo 9.1 CE y, consiguientemente, por la interpretación que de la misma hace el Tribunal Constitucional).

Pero, al igual que el respeto que merece el árbitro de un partido de fútbol no excluye que quepa la discrepancia sobre sus decisiones, nadie puede esperar que el Tribunal Constitucional deba ser inmune a las críticas ${ }^{3}$. Más bien, todo lo contrario. Es precisamente el inmenso poder que atesora este alto Tribunal el que aconseja que sus decisiones sean sometidas a un profundo escrutinio social, doctrinal y, cuando proceda, procesal.

Es cierto que el control social, canalizado fundamentalmente a través de la prensa, debe ser visto con cierta desconfianza, puesto que, desde hace ya mucho tiempo, los medios editoriales han dejado de ser instrumentos que transmiten informaciones para convertirse en privilegiados creadores de información, de intereses y de opinión ${ }^{4}$. Y la opinión pública es primaria en sus juicios (sometiendo, por lo general, los problemas técnicos a criterios ideológicos o partidistas) $y$, consiguientemente, fácilmente manipulable. Estos factores explican, por ejemplo, la inusitada reacción mostrada por la opinión pública ante la STEDH recaída en el asunto Inés del Río y las viscerales e injustas críticas vertidas contra el Juez español, el profesor López Guerra.

Distinto alcance presenta el control doctrinal, que se presume vertido por expertos en la materia y que se expresa a través de contribuciones científicas. A diferencia del anterior, se fundamenta en argumentos lógicos y se encuentra sometido, a su vez, al escrutinio de otros especialistas en las mismas materias.

Resulta tarea fácil concluir que las resoluciones del Tribunal Constitucional están sometidas al primario control social y al reposado control doctrinal. ¿Procesal también? ¿No se había indicado que sus resoluciones son infiscalizables por parte de otros

${ }^{3}$ El profesor Aguado Renedo recuerda la afirmación del Juez Jackson de que el carácter definitivo de la solución en los casos de que conozca el Tribunal Constitucional devendrá no de que intrínsecamente sea mejor, sino de que por encima de ella no puede haber otra que la modifique («Del intento...», cit., p. 10).

${ }^{4}$ Ver, por todos, EnTMAn, Robert: Democracy without citizens: media and the decay of American politics. Oxford University Press. Oxford, 1989. 
Tribunales? $?^{5}$ La realidad es más compleja a nuestro juicio, y con esto vamos entrando en materia, porque, de un lado, el Tribunal Europeo de Derechos Humanos puede separarse de decisiones adoptadas por el Tribunal Constitucional. Si bien es cierto que en los procesos abiertos ante el Consejo de Europa no se cuestiona su concreta actuación, sino la del Estado español, hay ocasiones en las que estamos en presencia de un profundo cuestionamiento de su labor. Pero es que además, es posible establecer un debate dentro del seno del Tribunal Constitucional que se encauza a través de los votos particulares, concordantes o discrepantes, que sus Magistrados puedan emitir.

¿Y con otros tribunales? ¿Puede un tribunal ordinario $-\mathrm{y}$ el Tribunal Supremo lo es, pese a su enorme importancia-, expresar una discrepancia con el enfoque utilizado por el alto Tribunal? Para dirimir adecuadamente esta cuestión podría deslindarse lo que las resoluciones del Tribunal Constitucional tienen de auctoritas y de potestas. Comenzando por esto último, resulta evidente que cualquier Tribunal está vinculado por la interpretación y las decisiones que se adoptan en Domenico Scarlatti. Ahora bien, ¿es posible asumir dichas posiciones de forma crítica, evidenciando las debilidades en la fundamentación de la resolución emitida por el Tribunal Constitucional que le han llevado a tomar esa decisión?

A mi juicio no solamente es posible, sino que, cuando se hace guardando el obligado respeto institucional, es conveniente. Me permitirán que les ponga un ejemplo concreto, porque creo que es mucho más revelador que mis torpes palabras. Les pido excusas, porque el asunto al que me voy a referir tiene que ver con la Sala de lo Penal del Tribunal Supremo, pero creo que merece la pena fundamentar lo que acabo de decir.

En la (por cierto, discutible) STC 237/2005/8, de 26 de septiembre se afirma que una lectura restrictiva del artículo 23.4 LOPJ lesiona el derecho a la tutela judicial efectiva, anulando la Sentencia del Tribunal Supremo de 25 de febrero de 2003. No nos interesa ahora ahondar ni en la justicia universal ni en la evolución posterior ${ }^{6}$ de este instituto, sino detenernos en la forma en que el Tribunal Supremo expresará su discrepancia ante esta decisión del Tribunal Constitucional.

Pues bien, en el FD 2 de la Sentencia 645/2006, de 20 de junio (recurso 1395/2005), el Tribunal Supremo acoge, como no puede ser de otra forma, la generosa visión de la justicia universal contenida en la STC 237/2005, afirman-

5 Dejamos de lado la reciente reforma del recurso de revisión en los distintos órdenes jurisdiccionales, que servirá para extraer consecuencias de las Sentencias del Tribunal Europeo de Derechos Humanos que hayan condenado al Reino de España.

${ }^{6}$ Instituto procesal que se ha visto modificado en 2009 (LO 1/2009) y 2014 (LO 1/2014). Ambas reformas han pretendido restringir el alcance de la justicia universal (imponiendo la existencia de puntos de conexión con España) y restringiendo la legitimación (puesto que se precisa la previa interposición de querella por el agraviado o por el Ministerio Fiscal). 
do que «el art. 23.4 LOPJ debe ser interpretado sin tomar en consideración ninguna articulación posible de este principio con otros del ordenamiento jurídico». Sin embargo, añade la Sala, «Esta decisión no nos impide mantener el diálogo institucional y constructivo que debe presidir la relación entre el Tribunal Constitucional y el Tribunal Supremo, invitando a aquél a un nuevo análisis de las cuestiones que el principio de la jurisdicción universal implica». Y a partir de este momento se abre una extensa y motivada argumentación que trata de evidenciar la debilidad de la construcción realizada por el Alto Tribunal.

Nos parece que esta forma de actuar resulta modélica, porque cohonesta, como no puede ser de otra forma, el respeto institucional que merecen las resoluciones emanadas del Tribunal Constitucional con la constructiva crítica de su contenido. Y que esa crítica provenga del Tribunal Supremo presenta también evidente interés porque estamos en presencia, no lo olvidemos, del «órgano jurisdiccional superior en todos los órdenes, salvo lo dispuesto en materia de garantías constitucionales» (artículo 123.1 CE).

Dicho con otras palabras, también el Tribunal Supremo merece ser oído a través de sus resoluciones cuando considere que una interpretación ofrecida por el Tribunal Constitucional es errónea o discutible. No es que estemos, a mi juicio, en presencia de un diálogo de tribunales, por más que esta expresión se haya puesto de moda, sino ante la defensa de las competencias propias en primer término, y del orden constitucional también ${ }^{7}$.

Ahora bien, es de justicia reseñar que no siempre se ha respetado esa labor del Tribunal Constitucional por parte del Tribunal Supremo. En efecto, se han producido algunos comportamientos que merecen ser descritos y criticados. Pero antes de entrar en esta tipología de comportamientos desafortunados por parte del Tribunal Supremo, conviene aclarar que las críticas vertidas sobre los excesos del Tribunal Constitucional pueden tener pleno sentido ${ }^{8}$. No se cuestiona, pues, la discrepancia, sino la forma de mostrarla.

7 Coincido plenamente con las reservas expresadas por Giuseppe Vergottini hacia este tópico tan extendido como discutible, en un trabajo (Más allá del diálogo entre tribunales. Comparación y relación entre jurisdicciones. Thomson. Madrid, 2011) del que tengo noticias gracias a Rosario Serra Cristóbal [ «Nuevos tiempos en las relaciones entre el Tribunal Supremo y el Tribunal Constitucional en España ¿De las desavenencias a una relación dialogada?». Anuario Iberoamericano de Justicia Constitucional 18 (2014), p. 376, nota 10], y de las que se separa la autora citada (ibidem, p. 377).

${ }^{8}$ Que tendrían su origen, al decir de Giuseppe Campanelli, en aquellos supuestos en los que el Tribunal Constitucional controla y reforma la legalidad ordinaria sin que exista en todos los casos un nexo claro entre este tipo de intervención y el contenido de un derecho fundamental invocado (en «I rapporti tra Tribunal Constitucional e Tribunal Supremo nell'ordinamento spagnolo». Rivista de Diritto Costituzionale 2002, p. 265). 


\section{LOS COMPORTAMIENTOS DISCUTIBLES ${ }^{9}$}

\subsection{Los Tribunales deben expresarse a través de resoluciones}

Como ya se ha indicado, el respeto institucional que el Tribunal Constitucional merece como órgano constitucional no es incompatible con la necesaria crítica que puedan merecer sus resoluciones. Sin embargo, dichas discrepancias suelen mostrarse, con naturalidad y de forma constructiva, en la actuación ordinaria de los Tribunales.

Esto no ha ocurrido siempre. Se recordará que cuando el Tribunal Constitucional dictó la STC 7/1994, de 17 de enero ${ }^{10}$, sobre la negativa del demandado

9 Seguiremos un recorrido histórico, pero porque coincide con nuestro interés, que es graduar de menos a más graves las reacciones del Tribunal Supremo frente a resoluciones, inevitablemente discutibles, del Tribunal Constitucional. No aludiremos aquí a la primera discrepancia profunda, sobre los requisitos de admisión del recurso de casación. Ver, sobre esta materia, Rubio Llorente, Francisco: «El guardián de la Constitución. Claves de la Razón Práctica 142 (2004), p. 18 y, con más detalle, Xiol Ríos, Juan Antonio: «La posición constitucional del Tribunal Supremo». En Trillo Torres, Ramón; Bacigalupo, Enrique y Lucas Murillo de la Cueva, Pablo (coords): El Tribunal Supremo en el ordenamiento constitucional. Jornadas en conmemoración del XXV Aniversario de la Constitución de 1978. Tribunal Supremo. Madrid, 2004, pp. 89 ss. Por cierto, dichos problemas no se han planteado únicamente en el ámbito civil, como acredita la lectura de Desdentado Bonete, Aurelio: «Sobre las difíciles relaciones entre el recurso de casación para la unificación de la doctrina y el recurso de amparo y sobre los problemas de prejudicialidad administrativa en el proceso social: Una reflexión crítica y una propuesta». Civitas. Revista Española de Derecho del Trabajo 78 (1996), pp. 687 ss. (ibidem, p. 89). Por su parte, Vicente Gimeno Sendra recuerda otras resoluciones del Tribunal Constitucional que fueron cuestionadas por el Supremo. Son las SSTC 31/1981, de 28 de julio (prohibición de condena con base en el interrogatorio policial), 166/1986 (RUMASA, por el intento de procesar a los Magistrados por su filtración a la prensa), (en «De nuevo », cit., pp. 106-107), que el autor vincula con una finalidad ideológica. Y Rafael Mendizábal añade a este a listado la STC 132/1993, de 20 de julio (sobre la excarcelación de la Mesa de Herri Batasuna) [en «La guerra de los jueces: Tribunal Supremo vs Tribunal Constitucional». Revista de Derecho Procesal 1 (2005), p. 514]. También aluden varios autores [ver por todos, Muñoz Campos, Juan: «Recurso de amparo frente a resoluciones judiciales: ¿ante el Tribunal Constitucional o ante el Tribunal Supremo?». La Ley 1 (1983), pp. 1238 ss.] al cambio de criterio operado por la STC (Sala Primera) 59/1982, de 28 de julio, respecto de las Sentencias del Tribunal Supremo de 14 de noviembre de 1979, 13 de enero y 30 de marzo de 1981 sobre la aplicación del principio de igualdad en el ámbito laboral.

${ }^{10}$ El Tribunal determina que «afirmar la necesidad de una prueba para comprobar la veracidad de las alegaciones de la demandante, y -legitimando la negativa del demandado a someterse a la prueba biológica sin actividades adicionales que tiendan a superar esta injustificada negativafallar sobre la base de que no se ha probado suficientemente, es una contradicción esencial» (FJ 7). Esta Sentencia generó multitud de comentarios doctrinales: Arias Rodríguez, José Manuel y Corrochano Jerez, Susana: «Reflexiones en torno a la STC 7/1994, de 7 de enero». Actualidad y 
civil a realizar una prueba de paternidad, la Sala Primera del Tribunal Supremo decidió presentar una queja formal ante el Rey, pidiéndole, junto a Magistrados de otras Salas ${ }^{11}$, que ejerciera su poder moderador. Los Magistrados denunciaban «su malestar e inquietud por la actuación del Tribunal Constitucional, al que responsabilizan de invadir la función jurisdiccional que, con arreglo a la Constitución, corresponde a los jueces y tribunales» ${ }^{12}$. Aunque esta medida puede ser calificada de insólita, debe recordarse que fue la menos incisiva de las propuestas por los Magistrados de dicha Sala ${ }^{13}$.

Esta decisión de la Sala Primera del Tribunal Supremo fue criticada en sede doctrinal ${ }^{14}$, y con razón, porque involucraba a nuestro Monarca en un problema

Derecho 6 (1995), pp. 1 ss.; Rivero Hernández, Francisco: «Una nueva doctrina sobre la obligación de sometimiento a la prueba biológica en los procesos de filiación». Revista de Derecho Procesal 33 (1994), pp. 349 ss.; Lledó Yague, Francisco: «La paternidad forzada: a propósito de la reciente Sentencia del Tribunal Constitucional de 19 de enero de 1994». Revista de Derecho y Genoma Humano 1 (1994), pp. 203 ss.; O’Callaghan MuÑoz, Xavier: «Negativa a la prueba biológica de la acción de investigación de la paternidad». Actualidad y Derecho 17 (1994), pp. 1 ss. y Bustos Pueche, Enrique: «Planteamiento técnico del conflicto entre Tribunal Supremo y Tribunal Constitucional». Diario La Ley 3601 (1994), pp. 1 ss.

11 Delgado del Rincón, Luis E: «Los conflictos entre la Sala Primera del Tribunal Supremo y el Tribunal Constitucional: génesis, evolución y algunas propuestas de solución». Revista General de Derecho Constitucional 4 (2007), p. 3.

${ }^{12}$ Utilizamos la expresión vertida por Bonifacio de la Cuadra en la noticia «El Tribunal Supremo apela al poder moderador del Rey contra un fallo del Constitucional», publicada en El País de 4 de febrero de 1994, y disponible en http://elpais.com/diario/1994/02/04/espana/760316428_850215.btml. Luis E. Delgado recuerda que el Presidente del Tribunal Supremo abortó la pretensión de someter este escrito al Rey y que propuso, en el Discurso leído con ocasión de la apertura del año judicial, excluir del amparo constitucional los derechos recogidos en el artículo 24 CE [En «Inviolabilidad frente a responsabilidad de los Magistrados del Tribunal Constitucional». Revista Española de Derecho Constitucional 72 (2004), p. 269]. El texto de este escrito se puede consultar en Álvarez Conde, Enrique: «Algunas reflexiones en torno a las relaciones entre la jurisdicción ordinaria y la jurisdicción constitucional: A propósito del pretendido conflicto entre la Sala Primera del Tribunal Supremo y el Tribunal Constitucional». En VV.AA: Estudios de derecho público en homenaje a Juan José Ruiz-Rico. Vol. II. Tecnos, Madrid, 1997, pp. 13351336.

13 Un Magistrado propuso incumplir la Sentencia del Alto Tribunal, confiriendo la posibilidad al demandado, declarado padre por Sentencia de la Audiencia Provincial (Sección Décima) de Madrid, de 26 febrero 1990, de que se sometiera a la prueba de paternidad (con apoyo en la tesis contenida en el VP suscrito por el Magistrado Cruz Villalón), y otros cuatro denunciar al Constitucional ante el Ministerio Fiscal por invasión de jurisdicción, pretensión que, a su juicio, debería ser sustanciada ante la Sala Segunda del Tribunal Supremo. Ambas ideas resultan desafortunadas porque resultan, en la práctica, inviables, al no existir una vía procesal para que se lleven a efecto.

${ }^{14}$ Especial difusión alcanzó el artículo del profesor Rubio Llorente publicado en El País el 9 de febrero de 1994, titulado «Supremo no hay y más que uno, pero no es el verdadero», disponi- 
de naturaleza eminentemente jurídica (esto es, técnico), un problema que, además, está resuelto expresamente en la Constitución, que dota al Tribunal Constitucional de competencia para anular resoluciones dictadas por el Tribunal Supremo. De ahí que la apelación al Rey solamente podía entenderse como un toque de atención dirigido al Tribunal Constitucional, encargado de delimitar el alcance de su propia jurisdicción.

\subsection{Los Tribunales deben respetar la doctrina constitucional}

Algunas resoluciones de la Sala de lo Penal del Tribunal Supremo han convertido una legítima discrepancia con determinadas motivaciones del Tribunal Constitucional en una inaceptable desobediencia a su doctrina.

Estamos ante un evidente salto cualitativo en relación con la simple queja que se quiso formular al Rey, porque en este caso ya se trata de subvertir el orden constitucional, que establece la vinculación de todos los poderes constituidos y de los ciudadanos a la Constitución (artículo 9.1), que es interpretada, en última instancia, por el Tribunal Constitucional. No resulta extraño, por ello, que el propio constituyente establezca que aquellas de sus resoluciones «que declaren la inconstitucionalidad de una ley o de una norma con fuerza de ley y todas las que no se limiten a la estimación subjetiva de un derecho, tienen plenos efectos frente a todos» (artículo 164.1 CE).

Pues bien, la Sala Segunda del Tribunal Supremo ha cuestionado la vinculación de Sentencias recaídas en recurso de amparo constitucional (aunque, como enseguida veremos, estas no se limitaban «a la estimación subjetiva de un derecho»).

Esto trató de hacerse en materia de justicia universal, en una Sentencia a la que ya hemos aludido con anterioridad. Pues bien, conviene recordar que en dicha Sentencia se incluye un Voto Particular suscrito por los Magistrados Saavedra Ruiz, García Pérez, Granados Pérez, Martínez Arrieta y Sánchez Melgar, en el que se cuestiona abiertamente que la interpretación contenida en la STC 237/2005, que anula la STS 327/2003, deba vincular al Tribunal Supremo. Se realiza, así, una peculiar interpretación del artículo $5.1 \mathrm{LOPJ}^{15}$ (peculiar porque en él se alude a

ble hoy en http://elpais.com/diario/1994/02/09/opinion/760748409_850215.html, y en el que afirmaba que «no existe, naturalmente, más Tribunal Supremo que aquel, que puede resolver los litigios desde la perspectiva de la norma más alta y de forma ya definitiva». Ver, también, Szmolka Vida, Inmaculada: El conflicto de competencias entre el Tribunal Supremo y el Tribunal Constitucional: la apelación al Rey como árbitro y moderador de las instituciones (febrero de 1994). Universidad de Granada. Granada, 1996. ISBN 84-89671-05-2.

15 Precepto que dispone «La Constitución es la norma suprema del ordenamiento jurídico, y vincula a todos los Jueces y Tribunales, quienes interpretarán y aplicarán las leyes y los reglamen- 
las resoluciones del Tribunal Constitucional dictadas en todo tipo de procesos), que lo vacía de contenido confiriendo, incomprensiblemente, un mayor protagonismo a la Ley Orgánica del Tribunal Constitucional. Entienden los Magistrados que algunos preceptos de esta Ley (artículos 38, apartados $1 .^{\circ}$ y $3 .^{\circ}, 40$ y 55 ) permiten separar los efectos de las resoluciones recaídas en procesos de control de control de constitucionalidad de las dictadas en amparo. En efecto, mientras que las Sentencias «dictadas en procedimientos de inconstitucionalidad vinculan a todos los poderes públicos y producen efectos generales», las recaídas en recursos de amparo «sólo vinculan al órgano jurisdiccional que conoce de la causa respecto a la que se suscitó este recurso, sin perjuicio de su indudable valor doctrinal y jurisprudencial». Estos Magistrados aceptan que el artículo 5.1 LOPJ amplia esta vinculación en un triple sentido (aludiendo a resoluciones y no únicamente a Sentencias; a todo tipo de procesos y no solamente los relacionadas con la constitucionalidad de las normas con fuerza de Ley y a los fundamentos de dichas resoluciones y no únicamente a su parte dispositiva), pero entienden que dicha extensión no es compatible con el artículo 117.1 CE (que somete a los órganos judiciales al imperio de la Ley, cuyo máximo intérprete es el Tribunal Supremo ex artículo 123.1 CE) ni amparable en lo previsto en el artículo 164.1 CE.

Resulta evidente que esta argumentación es manifiestamente inconsistente desde una perspectiva general, y estéril desde una dimensión práctica. Es inconsistente porque la referencia hecha a la Ley en el artículo 117 no debe vincularse a la Ley como concreto tipo normativo, sino a las normas que gozan, al

tos según los preceptos y principios constitucionales, conforme a la interpretación de los mismos que resulte de las resoluciones dictadas por el Tribunal Constitucional en todo tipo de procesos».

No vamos a profundizar en el análisis del artículo 5.1 LOPJ, precepto normativo que ha sido considerado como «inocuo e inútil» por Ignacio Díez-Picazo Giménez (en «Reflexiones sobre el contenido y efectos de las sentencias dictadas por el Tribunal Constitucional en recursos de amparo». En VV.AA: La Sentencia de amparo constitucional. Centro de Estudios Constitucionales. Madrid, 1996, p. 72). Nos parece más acertado afirmar, con Manuel Aragón Reyes, que los Tribunales ordinarios no podrán aplicar una interpretación de la Ley que ha sido considerada contraria a la Constitución por el Tribunal Constitucional o cuando considere que solamente hay una interpretación constitucionalmente admisible de la misma [en «Relaciones Tribunal ConstitucionalTribunal Supremo». Revista Española de Derecho Constitucional 76 (2006), p. 177].

En todo caso, el debate debe entenderse superado con la nueva regulación contenida en el artículo 40.2 LOTC, incorporado por la Ley Orgánica 6/2007, de 24 de mayo, que ahora dispone que, «en todo caso, la jurisprudencia de los tribunales de justicia recaída sobre leyes, disposiciones o actos enjuiciados por el Tribunal Constitucional habrá de entenderse corregida por la doctrina derivada de las sentencias y autos que resuelvan los procesos constitucionales». Ver, en el plano doctrinal, Aragón Reyes, Manuel: «Problemas de la justicia constitucional en España». En ARNALdo Alcubilla, Arnaldo y GonzÁlez-Trevijano, Pedro (dirs.): En pro de la regeneración política en España. Aranzadi. Madrid, 2015, p. 604. 
menos, con fuerza de Ley. Resulta evidente que una Sentencia que determina la interpretación constitucional que debe darse al artículo 23.4 LOPJ vincula a todos los órganos judiciales, siendo indiferente la vía procesal a través de la que el alto Tribunal se exprese. Decíamos que además de inconsistente es estéril, porque el Tribunal Constitucional siempre podrá anular las resoluciones que dicte el Tribunal Supremo si considera que su interpretación de la legalidad ordinaria provoca una lesión en los derechos fundamentales de las partes procesales.

No puede, pues, compartirse la rebelión pretendida por los Magistrados que suscriben el Voto Particular contra la doctrina del Tribunal Supremo. Entenderse, acaso sí. Se indica esto porque la Sala Penal ya se ha rebelado, pública y repetidamente, frente a otra doctrina establecida por el Tribunal Constitucional. Aludimos al clásico cómputo de la prescripción penal, que tanta polémica ha generado.

Como es bien sabido, el Tribunal Supremo entiende que la prescripción del delito se interrumpe cuando en una querella, denuncia o investigación se dirige contra una persona, identifica o identificable. Frente a este consolidado (y muy razonable ${ }^{16}$ ) criterio, el Tribunal Constitucional ha sostenido en su STC 63/2005 que hacía falta algo más para considerar dicha prescripción se interrumpa, y es que haya un acto judicial de admisión de la citada denuncia o querella ${ }^{17}$. Que esta Sentencia iba a ser polémica era evidente, dado que en ella se recuerda que el propio Tribunal se ha negado a revisar resoluciones similares (FJ 2) y se acompaña de sendos votos particulares que afirman que estamos ante una cuestión de estricta legalidad ordinaria ${ }^{18}$, aunque no excluyan todo control por parte del alto Tribunal.

${ }^{16}$ De hecho, me parece más acertada la lectura de la prescripción realizada por el Tribunal Supremo que la ofrecida por el Tribunal Constitucional, porque, como expresa atinadamente, José Manuel Chozas Alonso, provoca un «claro desarme de los sujetos individuales frente al Estado» [en « ¿Cuándo se interrumpe la prescripción en el ámbito procesal penal? (Un nuevo enfrentamiento entre el Tribunal Constitucional y el Tribunal Supremo)». Foro 2 (2005), p. 248]. Es de justicia reconocer que la situación ha mejorado con la reforma legal operada en esta materia, aunque sigue planteando algunos interrogantes de interés.

17 Siendo cierto que esta interpretación es más fiel al tenor literal empleado, en ese momento, en el artículo 132.2 del Código Penal en vigor (y, antes, en el 114 del Código Penal de 1973), resulta muy cuestionable que sea la más acertada, en la medida en que debilita el derecho pro actione de la acción penal. En todo caso, el Tribunal Constitucional ha reiterado esta doctrina en la Sentencia 29/2008, de 20 febrero.

${ }_{18}$ Muy claro en este sentido el emitido por el Magistrado Rodríguez Arriba, más matizado el debido al Magistrado Conde Martín de Hijas. 
Lo que nadie podía imaginar es que se iba a producir una clara negativa por parte del Tribunal Supremo a acoger esta nueva visión del Tribunal Constitucional, negativa que se iba a plasmar en el Acuerdo de Pleno no jurisdiccional de la Sala Segunda del Tribunal Supremo de 25 de abril de 2005 que se divide en dos puntos. En el primero se afirma que «El artículo 5.1 LOPJ, interpretado conforme a los arts. 117.1, 161.1b) y 164.1 CE, no puede impedir que el Tribunal Supremo ejerza con plena jurisdicción las facultades que directamente le confiere el art. 123.1 CE». Y en el segundo, aún más contundente, se acuerda «Mantener la actual jurisprudencia sobre la interrupción de la prescripción pese a la sentencia del Tribunal Constitucional 63/2005 ${ }^{19}$. Más allá del nulo valor jurídico que pueda conferirse a este tipo de Acuerdos $^{20}$, estamos en presencia de una manifiesta falta de respeto institucional hacia el Alto Tribunal, y ante una situación que genera, cuando menos, una desigualdad de trato jurídico en una materia especialmente sensible. Es verdad que la posición del Tribunal Supremo, que ha sido confirmada en diversas resoluciones judiciales posteriores ${ }^{21}$, se sustenta en razones de seguridad jurídica y justicia material, que son razonablemente atendibles. Resulta sin embargo inaceptable que se opte por desconocer una jurisprudencia constitucional, por más que sea ésta, cuando menos, discutible.

19 Dicho acuerdo puede consultarse en http://www.poderjudicial.es. Con posterioridad adoptó otro Acuerdo el 12 de mayo de 2005 en el que se afirmaba que «La Sala de lo Penal del Tribunal Supremo ha examinado la Sentencia del Tribunal Constitucional 63/2005 y considera que la misma insiste en la extensión de la jurisdicción constitucional basándose en una interpretación de la tutela judicial efectiva que, prácticamente, vacía de contenido el art. 123 de la Constitución Española que establece que el Tribunal Supremo es el órgano jurisdiccional superior en todos los órdenes, salvo lo dispuesto en materia de garantías constitucionales, por lo que, consiguientemente, le incumbe la interpretación en última instancia de las normas penales» (acuerdo este incluido en la compilación disponible en bttp://www.poderjudicial.es).

${ }^{20}$ Nos parecen muy razonables las consideraciones vertidas por Araceli Manjón-Cabeza Olmeda en ¿Son vinculantes los acuerdos del Pleno no jurisdiccional de la Sala Segunda del Tribunal Supremo?, publicado en la Revista Electrónica de Ciencia Penal y Criminología 10 (2008), pp. 02-1 y ss. Se trataría de meras recomendaciones que no provienen, en puridad, de un órgano judicial (sino de los jueces reunidos, lo que es parecido pero no es, en modo alguno, igual), y que no podrían desconocer ni la Constitución ni la Ley Orgánica ni afectar, restringiéndola, a la imparcialidad judicial. Y esta situación no puede verse alterada, obviamente, por el Acuerdo de 18 de julio de 2006 en el que se afirma que «Los acuerdos de la Sala General (Pleno no jurisdiccional) son vinculantes», puesto que los acuerdos, «al no tener fuerza para obligar, no pueden obligar a obligar» (ibidem, p. 18).

${ }^{21}$ SSTS de 19 de mayo de 2005, 25 de abril de 2006, y 21 de junio de 2006, citadas en García SÁnchez-Cervera, Eduardo y Peleteiro, Almudena: «Prescripción de los delitos. Divergencia de criterios entre el Tribunal Constitucional y el Tribunal Supremo». En Actualidad Jurídica Uría Menéndez 20 (2008), p. 73. 
El choque de trenes se volvió a producir tras la STC 29/2008, de 20 de febrero, en la que el Tribunal Constitucional podría haber dado un paso atrás, pero optó por reafirmar su cuestionable visión sobre la prescripción ${ }^{22}$. Y dicha actuación fue respondida con otro contundente (aún más, si cabe) Acuerdo no jurisdiccional del Pleno de la Sala Segunda del Tribunal Supremo de 26 de febrero de 2008, en el que se afirma que

«La Sala de lo Penal del Tribunal Supremo ha tenido conocimiento de la reciente sentencia dictada por la Sala Segunda del Tribunal Constitucional el pasado 20/02/08, que declara la nulidad de la nuestra de 14/03/03 y, tras su análisis, ratificamos nuestros precedentes Acuerdos de Sala General de 12/05/05 y 25/04/06, por cuanto el Órgano Constitucional reitera la extensión de su jurisdicción basándose de nuevo en una interpretación de la tutela judicial efectiva, en este caso, en relación con el potencial derecho a la libertad personal de los recurrentes, que vacía de contenido el art. $123 \mathrm{CE}$.

Este precepto constitucional, dentro del Título correspondiente al Poder Judicial, tiene como misión preservar el debido equilibrio entre órganos constitucionales del Estado, en este caso, el Tribunal Constitucional y el Tribunal Supremo, para asegurar el adecuado funcionamiento de aquél, de forma que se desconoce su esencia, fijando una interpretación de la legalidad ordinaria que sólo corresponde al Tribunal Supremo».

Afortunadamente, tras nuevos incidentes ${ }^{23}$, el legislador ha superado esta declaración de guerra institucional (en todo caso, desafortunada) regulando con mucho más detalle la institución material de la prescripción penal a través de la Ley Orgánica 5/2010, de 22 de junio ${ }^{24}$. Esta nueva normativa no ha impedido que el Tribunal Constitucional se haya visto obligado a otorgar amparo a perso-

\footnotetext{
${ }^{22}$ La Sentencia se acompaña de un Voto Particular emitido por el Magistrado Ramón Rodríguez Arribas, que sigue la estela del anteriormente aludido.

${ }^{23}$ El Tribunal Constitucional se ha visto obligado a anular la STS (Sala de lo Penal) 843/2006, de 24 de julio, en la que se ha negado expresamente a acoger su visión de la prescripción penal en la STC 195/2009. Debe recordarse que acompañan tres interesantes Votos Particulares a la Sentencia del Supremo (uno defendiendo el planteamiento de una cuestión de inconstitucionalidad por la falta de certeza del precepto penal que regula la prescripción - Bacigalupo Zapater-, y otros dos en los que los Magistrados expresan su acuerdo con la interpretación del Tribunal Constitucional, si bien uno de ellos - Maza Martín - cuestiona el principio general de vinculación entre ambas jurisdicciones) y uno a la del Constitucional (firmado por el Magistrado Rodríguez Arribas, por entender que el alto Tribunal no debe inmiscuirse en cuestiones de estricta legalidad).

${ }^{24}$ Paradójicamente, la nueva regulación, que trata de aunar las lecturas realizadas por los dos tribunales, es menos garantista que la defendida por el Tribunal Supremo, en la que medida en que deja un margen de actuación en el órgano judicial.
} 
nas que se han visto perjudicadas por una actuación dudosamente conforme a Derecho de determinados órganos judiciales.

Especial interés presenta la STC 32/2013, de 11 de febrero, en la que se enjuicia el hecho de que «la Sección Tercera de la Audiencia Provincial de Asturias, tras exponer la discrepante doctrina del Tribunal Supremo y del Tribunal Constitucional respecto de esta materia, considera, en su Sentencia, prevalente la doctrina del Tribunal Supremo (remitiéndose al Acuerdo del Pleno no jurisdiccional del Tribunal Supremo de 25 de abril de 2006) y, en consecuencia, entiende que no se ha producido la prescripción toda vez que toma en consideración la fecha de presentación de la querella (26 de enero de 2006) como momento de interrupción de dicha prescripción, rechazando de forma expresa la doctrina constitucional sentada en las citadas SSTC 63/2005 y 29/2008, en las que el Tribunal Constitucional sostiene, como ya se ha reproducido, que la simple presentación de una denuncia o querella, sin que medie ningún acto de interposición judicial, no puede interrumpir el plazo de prescripción, pues ello implicaría una falta de respeto a las exigencias de tutela reforzada (FJ 4).

Como resulta evidente, y hace notar el Ministerio Fiscal, «las resoluciones impugnadas incurren en manifiesto desconocimiento del deber de acatamiento de la doctrina del Tribunal Constitucional, lo cual supone una quiebra patente del mandato recogido en el aludido art. 5.1 LOPJ, de la que deriva la consiguiente lesión del derecho de la demandante a la tutela judicial efectiva consagrada en el art. 24.1 CE (SSTC 29/2008, FJ 10; 147/2009, de 15 de junio, FJ 2; 195/2009, de 28 de septiembre, FJ 6, 206/2009, de 23 de noviembre, FJ 3, y 133/2011, FJ 4, entre otras)» (Ídem).

El interés de esta resolución radica en que se pueden plantear algunas preguntas interesantes: ¿pueden los afectados reclamar al Ministerio de Justicia una reparación por los gastos ocasionados por un recurso que tiene su origen en un «desconocimiento del deber de acatamiento de la doctrina del Tribunal Constitucional»? ¿Incurren los Magistrados en alguna responsabilidad derivada de su actuación? No me atrevo a responder ninguna de estas preguntas. De un lado, porque carezco de unos mínimos conocimientos sobre estas materias que me permitieran avanzar una posición inicial. De otro porque se alejan del objeto del presente estudio. Sí me atrevo a afirmar mi extrañeza de que actuaciones como la descrita ${ }^{25}$ no generen ningún tipo de responsabilidad en un Estado de Derecho.

${ }^{25}$ Algo parecido ha ocurrido en relación con la Sala de lo Civil del Tribunal Supremo, en lo que atañe al recurso de casación. La STC (Sala Primera) 212/1994, de 13 de julio causó un gran malestar el Tribunal Supremo que, en el ATS (Sala Primera), al imponer un trámite de audiencia antes de la inadmisión del recurso de casación. Pues bien, la Sala de lo Civil adoptó un Acuerdo el 22 de septiembre de 1994 en el acordó no considerarse vinculado por la citada Sentencia del 
Aunque podría parecer que lo descrito es lo más grave de lo sucedido, lo cierto es que la Sala de lo Civil del Tribunal Supremo ha dado un paso más. Un paso que, aquí sí que estoy seguro, debería haber generado una responsabilidad en la actuación de los Magistrados.

\subsection{Un Tribunal no puede controlar la actuación jurisdiccional de los Magistrados del Tribunal Constitucional}

El affaire más grave del que daremos noticia en estas páginas se vincula con una muy desafortunada actuación de la Sala de lo Civil del Tribunal Supremo que, paradójicamente, tiene su origen en un asunto, en principio, menor. En efecto, lo que se cuestiona en sede judicial es si un reportaje de una Revista del corazón que tiene su origen en las declaraciones realizada por una ex-empleada del hogar de Isabel Preysler afecta, o no, a su intimidad personal. La posición del Tribunal Supremo es que «las frases aparecidas en el reportaje de la revista en cuestión como eran «...los granos que le salen en la cara, con frecuencia...», «... llevar una determinada agenda de piel de cocodrilo...», así como detalles de los hábitos de lectura, de la ropa que posee en los armarios, el horario familiar y los menús, todos ellos referidos a la señora P. A., datos, todos ellos proporcionados por una antigua doméstica; no se pueden catalogar, ni de lejos, como atentatorios graves a la intimidad, por ser afrentosos, molestos, o simplemente desmerecedores desde un punto de vista de homologación social. Simplemente constituyen una propagación de chismes de escasa entidad, que en algún caso pudieran servir como base para resolver un contrato laboral de empleo del hogar, pero nunca para estimarlos como un atentado grave y perjudicial a la intimidad de una persona» ${ }^{26}$.

No comparte este criterio el Tribunal Constitucional, por considerar que «de la lectura del reportaje publicado en la revista «Lecturas» se desprende con claridad que las declaraciones que se contienen en el mismo han invadido ilegítimamente la esfera de la intimidad personal y familiar de la recurrente, al dar al público conocimiento de datos y circunstancias que a este ámbito indudablemente pertenecen ${ }^{27}$. Además de alcanzar esta conclusión a la vista de los datos

Tribunal Constitucional, y al que se alude en el ATS (Sala de lo Civil) de 10 enero 1995 (RJ $1995 \backslash 9990$, FD 3). Como recuerda César Aguado, el Tribunal Constitucional varió su jurisprudencia en la materia con la STC (Pleno) 37/1995, de 7 de febrero (en «Del intento », cit., p. 27, nota 45). Ver también Mendizábal Allende, Rafael: «La guerra...», cit., p. 503.

26 STS (Sala Primera) 1157/1996, de 31 diciembre (RJ 1996〕226), FD 1.

27 STC $115 / 2000 / 5$, de 10 de mayo. 
suministrados $^{28}$, se hace especial hincapié en el deber de reserva de la ex empleada de la recurrente, pues la Ley Orgánica 1/1982, de 5 de mayo, veda la intromisión de aquéllas personas que revelen datos de una familia conocidos a través de una actividad profesional (art. 7.4) (FJ 6). A nuestro juicio, este último criterio debería haberse presentado como la ratio decidendi en el presente caso, puesto que, como es bien sabido, existe un especial deber de reserva en aquéllas personas que trabajan en los espacios destinados a la vida íntima personal y familiar. En tales supuestos, el rigor en la aplicación del precepto legal citado se impone con especial contundencia, porque los datos revelados solamente se han podido obtener en virtud de una profesión que lleva lógicamente aparejada un deber de reserva y en un contexto donde los titulares de los derechos afectados actúan con plena libertad por hacerlo en espacios protegidos constitucionalmente (a través de la inviolabilidad del domicilio).

En todo caso, estaremos de acuerdo en que estamos ante una divergencia de criterio menor. El Tribunal Constitucional opta por amparar a Isabel Preysler y anular la Sentencia del Tribunal Supremo para que éste dicte una nueva resolución respetuosa con el derecho fundamental invocado. Dicho respeto supone, en la práctica, dos cosas. Una, reconocer la lesión del derecho fundamental a la intimidad ya decretada por el Tribunal Constitucional. Otra, acordar una indemnización. Sobre ésta conviene recordar que la recurrente había solicitado, en principio, cincuenta millones de pesetas. El Juzgado de Primera Instancia 32 de Barcelona dio la razón a la recurrente por Sentencia de 23 de mayo de 1991, acordando una indemnización de cinco millones de pesetas. Dicha indemnización fue duplicada en apelación, por Sentencia de la Audiencia Provincial de Barcelona de 12 de enero de $1993^{29}$.

Pues bien, cuando la Sala de lo Civil del Tribunal Supremo debe reconsiderar su decisión adoptada, no lo hace ni de forma respetuosa ni de forma acertada. En efecto, la STS 776/2000, de 20 julio $^{30}$ acepta (no le queda otro remedio) que el reportaje cuestionado «supone un ataque a la intimidad» de la recurrente (FD 1). Ahora bien, «La valoración pecuniaria de la responsabilidad de quien lesiona el derecho fundamental a la intimidad, estará determinada por la gravedad atentatoria de dicho ataque, así como por la difusión de la noticia y las ventajas económicas obtenidas con ella» (FD 2). Pues bien, «las frases «granos que le

${ }^{28}$ Son íntimos, por ejemplo, los datos sobre defectos, reales o supuestos en el cuerpo, los cuidados que estos requieren, la divulgación de los efectos negativos de un embarazo sobre su belleza, la amplia descripción de su vida diaria y de sus hábitos en el hogar, y los referidos a sus relaciones con sus exmaridos y sus hijos (idem).

29 Datos extraídos del Antecedente 2 de la STC 115/2000/5, de 10 de mayo.

30 RJ $2000 \backslash 6184$. 
salen en la cara..., determinada agenda de piel de cocodrilo..., ropa que posee...» se pueden calificar como insignificantes dada la enorme proyección pública de la afectada -hecho notorio-, por lo cual la valoración del daño moral producido puede ser mesurado en 25.000 pesetas. La difusión de la noticia y las ventajas reportadas, no han podido ser cuantificadas económicamente» (FD 2).

No resulta complejo establecer la manifiesta debilidad de esta argumentación. En primer lugar, porque una lesión de un derecho fundamental nunca puede ser calificada de insignificante. En segundo lugar, porque el Tribunal Constitucional descarta expresamente (STC 115/2000/10, de 10 de mayo) que la relevancia pública de la recurrente y su previa divulgación de datos íntimos legitime la agresión sufrida. Y en tercer y último lugar, porque el hecho de que no haya una pericial sobre el beneficio obtenido por la Revista Lecturas por la difusión de esta noticia no impide que cualquier persona sepa que es muy superior a la cifra acordada de 25.000 pesetas. Cantidad que supone, conviene recordarlo, un, $0,5 \%$ de la indemnización conferida en la instancia y un 0,25 de la otorgada en apelación.

No resulta extraño que la recurrente volviera a interponer una demanda de amparo, por indebida ejecución de la STC 115/2000 y por la presunta lesión de los derechos a la intimidad personal y a la tutela judicial efectiva, por determinar el quantum indemnizatorio con una argumentación irrazonable y separada de la acordada, motivadamente, en las resoluciones de instancia y apelación. Se interesa que se declare ajustada a indemnización la otorgada por la Audiencia Provincial de Barcelona ${ }^{31}$.

Aunque la nueva Sentencia del Tribunal Constitucional (186/2001, de 17 de septiembre) merecería un comentario autónomo por diversas razones ${ }^{32}$, nos centraremos en lo que nos interesa en el marco de esta investigación. Pues bien, con una discutible argumentación, el alto Tribunal entiende que la nueva Sentencia del Tribunal Supremo no ha vulnerado el derecho a la tutela judicial efectiva, pero sí el derecho a la intimidad personal.

La primera afirmación, muy endeble en la Sentencia, se justifica en que el Tribunal Supremo puede variar, y ha variado en muchas ocasiones, el quantum indemnizatorio fijado en otras instancias (FJ 4). Es cierto, sin embargo, que el

${ }^{31}$ Información extraída del Antecedente Tercero de la STC 186/2001, de 17 de septiembre.

32 Dos cuestiones generan un evidente interés. ¿Puede vulnerarse un derecho fundamental aunque se haya reconocido su lesión en la resolución judicial que se impugna en amparo? Y, ¿la indemnización que genera la lesión de un derecho fundamental forma parte del mismo derecho fundamental? Ver, en el plano doctrinal, Gimeno Sendra, Vicente: «De nuevo el conflicto entre el Tribunal Supremo y el Tribunal Constitucional». La Ley 7 (2001), pp. 1363 ss. y Persona y Derecho 44 (2001), pp. 103 ss. 
Tribunal Supremo ha fijado la indemnización sin tener en cuenta «los criterios o parámetros básicos legalmente exigidos» (FJ 5). Por ejemplo, si bien resulta cierto que los beneficios económicos no quedaron acreditaos, existían «datos relevantes respecto de la difusión de la revista en la que dicho reportaje se incluyó » ${ }^{33}$, concluyendo que el Tribunal redujo muy significativamente la indemnización «sin valorar las circunstancias del caso y sin utilizar para determinar la gravedad de la lesión el criterio de la difusión, probada en el proceso, de la revista en la que se publicó el reportaje considerado» (FJ 5 in fine). A la vista de estos criterios, «el razonamiento del Tribunal Supremo no constituye una motivación adecuada o satisfactoria de la decisión adoptada (por todas, STC 214/2000, de 18 de septiembre, FJ 4), y por ello, en la medida en que puedan considerarse lesión autónoma respecto del derecho a la intimidad, podría suponer una vulneración del derecho de la recurrente a obtener de los órganos judiciales una resolución motivada y fundada en Derecho» (FJ 6). Debemos subrayar ahora el «podría suponer una vulneración», porque no se encontrará en el fallo de la Sentencia que resumimos la estimación del amparo en lo que atañe al derecho a la tutela judicial efectiva.

El Tribunal Constitucional estima, en relación con el segundo derecho invocado, que «una indemnización de 25.000 pesetas resulta insuficiente para reparar el derecho a la intimidad personal y familiar de la recurrente» (FJ 7), por lo que considera vulnerado este derecho fundamental. Pero también incide en esta lesión el apartamiento en la resolución judicial impugnada de los criterios fijados por la STC 115/2000 en orden a delimitar el alcance del derecho fundamental y fijar la indemnización (FJ 7 in fine). En efecto, se omite en la nueva Sentencia del Tribunal Supremo el hecho «de que la divulgación de los datos había sido realizada quebrantando el deber de secreto impuesto a las personas que conviven en el hogar de una persona por razones laborales», la relevancia constitucional del derecho fundamental vulnerado y la correlativa exigencia de una reparación acorde con el relieve de los valores e intereses en juego (FJ 8). En conclusión, la Sentencia del Tribunal Supremo no solamente no repara el derecho fundamental, sino que vuelve a vulnerarlo.

Aunque lo procedente habría sido, en principio, devolver nuevamente la causa a la Sala de lo Civil del Tribunal Supremo para que este fijara una nueva indemnización ajustada a Derecho, la Sala Segunda del Tribunal Constitucional acuerda decretar la nulidad de la Sentencia impugnada y otorgar firmeza a la dictada, en su día, por la Audiencia Provincial de Barcelona. Se pretende, así,

33 FJ 5. Son datos tales como que la Revista tuvo una difusión de entre 331.934 y 435.716 ejemplares, o que se difundieron dichas informaciones en doce entregas semanales consecutivas, o que la recurrente ocupó un lugar preferente en la portada de la publicación... 
«excluir dicha devolución con el objeto de que la reparación procedente no se dilate en términos inadmisibles al resultar remitida a un proceso que puede prolongarse indefinidamente y que, en consecuencia, por su misma duración, podría hacer ilusoria la obligada reparación del derecho fundamental lesionado» (FJ 9).

De esta última decisión discrepan los Magistrados Conde Martín de Hijas y Jiménez Sánchez a través del oportuno Voto Particular. Estiman, de un lado, que se debió estimar lesionado el derecho a la tutela judicial efectiva y, de otro, que el asunto debió volver al conocimiento del Tribunal Supremo una vez anulada la Sentencia impugnada. La ausencia o carencia de motivación de la resolución judicial impugnada debería haber sido constatada por el Tribunal Constitucional, anulándola y devolviendo las actuaciones al Supremo para que dictara una nueva Sentencia que se ajustara a las exigencias derivadas del citado derecho fundamental. Confiriendo firmeza a la Sentencia recaída en apelación, el Tribunal Constitucional se ha implicado en «ámbitos propios del ejercicio de la jurisdicción».

A mi juicio, esquizofrénico como enseguida se verá, tienen razón los Magistrados en el primer punto pero no en el segundo. Resulta patente la vulneración del derecho de la recurrente a recibir una resolución motivada por parte del Tribunal Supremo. Evidente no sólo para los Magistrados discrepantes, intuyo, sino para todos los miembros de la Sala. El hecho de que la mayoría haya optado por reconocer una lesión de un derecho material y no de un derecho procesal podría ser, precisamente, la de evitar la devolución de la causa al Tribunal Supre$\mathrm{mo}^{34}$. Lo más correcto hubiera sido reconocer esa lesión procesal, pero entiendo que, en este caso, en el que ya la Sala de lo Civil había dado expresas muestras de no acatar la previa resolución recaída en amparo, procedía, en aras a que éste fuera efectivo en un plazo razonable, conferir firmeza a la Sentencia de la Audiencia Provincial de Barcelona. Asumo, pues, la crítica inicial de los Magistrados discrepantes, pero me separo de su (lógica) consecuencia.

Resulta lógico pensar que la STC 186/2001 no causara una gran alegría entre los Magistrados de la Sala Primera del Tribunal Supremo, aunque diera una respuesta razonable a la efectividad de los derechos fundamentales invocados por la recurrente ${ }^{35}$. Lo que nadie podía sospechar es que su actuación iba a ser tan desafortunada y desmedida.

${ }^{34}$ En efecto, cuando el Tribunal Constitucional anula una resolución judicial por ausencia o carencia de motivación, o por no satisfacer las exigencias constitucionales, se suele anular y retrotraer las actuaciones para que el mismo Tribunal apruebe una nueva resolución respetuosa con el citado derecho fundamental.

35 Es oportuno recordar que la demanda interpuesta por Bou Gisbert y El Hogar y la Moda, S.A., contra España ante el Tribunal Europeo de Derechos Humanos fue inadmitida por Decisión de la Sección Cuarta de 13 de mayo de 2003 (TEDH 2003\52). Sobre esta resolución puede con- 
Vayamos por partes. La Sentencia de la Sala de lo Civil 1064/2001 de 5 de noviembre (RJ 2006 677), referida a un asunto distinto pero cercano, que tendría un posterior discurrir muy parecido al acaecido con el asunto Presyler ${ }^{36}$, contiene una respuesta directa a la STC ${ }^{37}$. Es sorprendente que así sea porque el supuesto enjuiciado es cercano, si bien distinto. Esto explica que el Magistrado

sultarse Salvador Coderch, Pablo y otros: «Preysler V: el final de la partida». Working Paper 170, disponible en bttp://www.Indret.com.

${ }^{36}$ Alberto de Alcocer Torra interpone juicio de protección de los derechos fundamentales por la publicación de algunas fotos en la Revista Diez Minutos por considerar que lesionan sus derechos a la intimidad y a la propia imagen. El Juzgado de Primera Instancia 6 de Madrid (Sentencia de 9 de septiembre de 1991) estima su demanda y establece una indemnización de veinte millones de pesetas. Aunque esta resolución fue confirmada en apelación (Sentencia de la Audiencia Provincial de Madrid de 27 de septiembre de 1993), el Tribunal Supremo (Sentencia de 17 de diciembre de 1996) entendió que no se había producido lesión alguna en sus derechos fundamentales, al tratarse el demandante de persona pública, darse un interés general de la información y haberse tomado la imagen en un lugar público (una playa). La STC 83/2002, de 22 de abril, discrepa de esta construcción, porque el órgano judicial no ha tenido «en cuenta, en su juicio de ponderación, la naturaleza privada y el carácter personal y familiar de las fotografías ni su forma de obtención, mediante una operación ajena a la voluntad del actor y sin su consentimiento, razones por las cuales no es adecuado, pues no ha ponderado el derecho a la propia imagen del recurrente y el derecho a comunicar información, respetando la definición constitucional de cada derecho y sus límites» (FJ 4). Como dicha imagen reveló además sus relaciones afectivas se estima igualmente vulnerado su derecho a la intimidad personal. Es en este momento cuando el Tribunal Supremo dicta la resolución examinada en el texto, que, acordando una indemnización de doscientos euros, será nuevamente impugnada ante el Tribunal Constitucional, lo que originará la STC 300/2006, de 23 de octubre, que estimara que se ha producido una nueva lesión de los derechos a la intimidad personal y a la propia imagen, anulando la Sentencia del Tribunal Supremo y confiriendo firmeza a la dictada en apelación. El Magistrado Pérez Tremps considera, en su Voto Particular, que hubiera sido más acertado sustanciar la pretensión como incidente de ejecución de la Sentencia dictada cuatro años antes, y que no se ha vulnerado el derecho fundamental invocado, puesto que el Tribunal Supremo razonó el quantum indemnizatorio.

37 Una tercera saga similar (Alberto Cortina), que nos limitamos a rememorar, viene marcada por las actuaciones de Alberto Cortina de Alcocer contra la publicación de imágenes tomadas durante un viaje que había realizado a Kenya con una mujer. Son las Sentencias del Juzgado de Primera Instancia 8 de Madrid de 22 de enero de 1992 (estimatoria), de la Audiencia Provincial de Madrid de 12 de julio de 1993 (confirmatoria, indemnización de ocho millones de pesetas) (AC 1993\1554), casada por Sentencia del Tribunal Supremo 905/1997, de 21 de octubre (RJ 1997\176). Esta Sentencia fue anulada por la STC (Sala Primera) 139/2001, de 18 de junio (RTC 2001\139), que ha sido objeto de diversos comentarios, como son los debidos a Asunción de la Iglesia Chamarro [ «El derecho a la propia imagen de los personajes públicos». Revista Española de Derecho Constitucional 23 (2003), pp. 285 ss.] y M. Ángeles Fernández González-Regueral [«Protección civil y constitucional del derecho a la imagen». Actualidad Civil 20(2002), pp. 689 ss.]. Es conveniente recordar, en último lugar, que en esta Sentencia del Tribunal Supremo se estima la lesión de la intimidad «por imperativo legal», para dejar clara la discrepancia de la Sala con el Tribunal Constitucional (FD 1). 
Marín Castán se separe de esta parte de la Sentencia, «por no guardar relación con los motivos del recurso ni ser consecuencia de la estimación de ninguno de ellos, ya que todos son desestimados».

Pues bien, para «evitar suspicacias y salir, ahora, al paso de cualquier tacha de empecinamiento, que se expresen las razones de disconformidad con la sentencia del Tribunal Constitucional dictada en el recurso de amparo número 5002/2000 (Sala Segunda) - por cierto, dictada con una rapidez inusitada en relación a otras peticiones de amparo, lo que sin duda tendrá alguna explicación—, y que invalidó la indemnización acordada en favor de Isabel P.; todo ello por entender que la misma invadió las funciones de la jurisdicción ordinaria de manera contraria, incluso, a las propias normas orgánicas que rigen dicho Tribunal Constitucional» (FD 2). Y es que la Sala considera «cabalmente acertado el criterio seguido en su resolución anterior», que pretende argumentar de forma detenida, afirmando que:

a) Las sentencias del Tribunal Constitucional que han otorgado doblemente amparo a Isabel P., frente a las dos sentencias de esta Sala, incurren en palmaria contradicción, por considerar la primera irrelevante que los datos aportados sean o no desmerecedores y afirmar su gravedad en la segunda.

b) La más reciente Sentencia del Tribunal Constitucional contiene razonamientos inaceptables, desconoce el concepto de instancia procesal e incurre en el error mayúsculo, inexcusable por su índole, de hacer valer una sentencia inexistente (puesto que fue revocada) por encima de la decisión del Tribunal Supremo, cuyos hechos debían ser respetados por el alto Tribunal. Después de estas amables consideraciones críticas, la Sala defiende que se limitó a valorar libremente la prueba y que la indemnización fijada no era simbólica. Tras poner un buen número de ejemplos, se recuerda asimismo listado de cantidades recogido en la Ley 30/1995 con el mismo fin.

c) También se reprocha a esta Sentencia que se alteren los hechos probados, hurtando las funciones del Tribunal Supremo, lo que vulnera el artículo 54 LOTC. Y todo "porque los hechos que quería el Tribunal Constitucional que diéramos por probados, a su gusto, no aparecen declarados así».

d) Finalmente se critica que se convierta un vicio procesal en un vicio in iudicando y que se exprese una «inaceptable sospecha o desconfianza respecto de la conducta» del Tribunal Supremo cuando se acuerda no devolver las actuaciones para su posterior pronunciamiento.

Todas estas ideas, contenidas en el FD 2, se expresan «con la esperanza de que el Tribunal Constitucional medite sobre la importancia de las mismas sin llevar a sus últimas consecuencias lo que entendemos como conducta negligente que, con su repetición, sugeriría la concurrencia al menos de culpa con representación» o dolo eventual». 
La diatriba intolerable ${ }^{38}$ sigue $^{39}$, pero es suficiente quedarnos ahora con esta, primera, amenaza. Amenaza que ejercería con ocasión de que se juntaran el pan con las ganas de comer. Con esta imagen hacemos referencia al abogado José Luis Mazón, que también ha mostrado una especial fijación con el Tribunal Constitucional. Sin entrar ahora en su exégesis ${ }^{40}$ ni detenernos tampoco en sus secuelas, conviene recordar que este letrado interpuso una demanda de responsabilidad civil contra los Magistrados del Tribunal Constitucional ante la Sala Primera del Tribunal Supremo.

Aunque esta demanda tenía su origen en una muy desafortunada demanda de amparo, en la que se interesaba un absurdo lógico ${ }^{41}$, la Sala de lo Civil del Tribunal Supremo no perdió la ocasión de llevar su amenaza a término ${ }^{42}$. Tras determinar que a los Magistrados del Tribunal Constitucional no se les puede aplicar el artículo 411 de la Ley Orgánica del Poder Judicial ${ }^{43}$, entiende que sí

${ }^{38}$ Comparto la expresión vertida por Luis E. Delgado del Rincón en «Inviolabilidad », cit., p. 270.

39 En el FD 3 se cuestiona cuál debe ser el correcto entendimiento de la exigencia de motivación y en denunciar la, a su juicio, descalificación que se hace de la Sala Primera del Tribunal Supremo en el Voto Particular suscrito por los Magistrados Conde Martín de Hijas y Jiménez Sánchez.

${ }^{40}$ Esa fijación tiene su origen en la práctica del Tribunal Constitucional de optar por el reclutamiento de Letrados de adscripción temporal en vez de recurrir a la convocatoria de concursos-oposiciones. A juicio del citado Letrado, este comportamiento obstaculiza el derecho potencial de todo licenciado en Derecho a concurrir a dichas pruebas. La Sala Tercera del Tribunal Supremo ha desestimado esta pretensión en las Sentencias de 21 de enero y de 24 de junio de 2002 (RJ 2002\7058), aunque dos Magistrados (Trillo Torres y Maurandi Guillén) consideran que la figura del Letrado de adscripción temporal carece de cobertura legal. Ver, en el plano doctrinal, Rodríguez Patrón, Patricia: «Sobre la legalidad de los Letrados de adscripción temporal del Tribunal Constitucional». Revista Española de Derecho Constitucional 67 (2003), pp. 317 ss.

${ }^{41}$ El recurrente interesaba, en el recurso de amparo formulado contra la STS (Sala Tercera) de 24 de junio de 2002: (a) la abstención de todos los Magistrados del Tribunal Constitucional; (b) la presentación de un Proyecto de Ley por parte del Presidente del Gobierno que garantizara un examen imparcial de la demanda de amparo; (c) la estimación del presente amparo por la formación que prevea esa medida legislativa. Dado que la demanda tenía como destinatario a un órgano inexistente, el Pleno del Tribunal Constitucional acordó el archivo de las actuaciones. Contra el mismo el recurrente interpuso un (improcedente) recurso de súplica que, pese a todo, fue atendido mediante acuerdo de 17 de septiembre de 2002, en el que se insiste en que el propio recurrente ha optado por dirigir su demanda ante un Tribunal diferente, y que, además, no era ni clara ni precisa en su contenido, lo que determina el archivo de las actuaciones.

42 STS (Sala de lo Civil) 51/2004, de 23 enero (RJ 2004\1). Ver, en el plano doctrinal, DeLGADO DEL Rincón, Luis E: «Inviolabilidad...», cit.; AguAdo Renedo, César: «Del intento », cit., y CORTÉs Domínguez, Valentín: «Aproximación crítica a la situación jurídico-procesal creada por la Sentencia 51/2004 del Tribunal Supremo (Sala Primera)». Teoría y Realidad Constitucional 14 (2004).

43 Precepto derogado por la LO 7/2015, de 21 de julio, por la que se modifica la Ley Orgánica 6/1985, de 1 de julio, del Poder Judicial. Esta Ley suprime la responsabilidad civil y regula ahora la cuestión en el artículo 296 LOPJ. 
están sometidos a la responsabilidad extracontractual recogida en el artículo 1902 del Código Civil ${ }^{44}$. Para su concurrencia resulta preciso el cumplimiento de tres requisitos: una conducta activa o pasiva que, en el ejercicio de su función, sea antijurídica y culpable, la causación de un daño y la existencia de relación o nexo causal entre dicha conducta u omisión y el daño infringido.

A juicio, manifiestamente desafortunado, del Tribunal Supremo se cumplieron los tres requisitos. En primer lugar, porque «los Magistrados en cuestión se negaron lisa y llanamente a entrar a resolver una petición de amparo so pretexto de que iba dirigida a un hipotético tribunal, lo que implica un non liquet totalmente inadmisible». Afirmación torticera, porque la providencia era perfectamente congruente con la demanda interpuesta, falsa la de que «no se ha dado respuesta a la pretensión de amparo» ${ }^{45}$, y especialmente grave la de que «los Magistrados demandados han actuado con una negligencia profesional grave, que supone, para el caso concreto, una ignorancia inexcusable, ya que la ilicitud o antijuridicidad tiene como base la violación de unas normas absolutamente imperativas ${ }^{46}$. De ahí que exista una culpa grave en la actuación de los Magistrados del Tribunal Constitucional.

Pero, ¿cuál es el daño que tan irresponsable actuación —entiéndase la ironíaha provocado? Pues ahí es nada: «hacer que se tambaleen sus creencias [, las del recurrente] como ciudadano de un Estado social y democrático, que, entre otras cosas, propugna la justicia como valor superior, y España es un Estado que reúne dichas características según el artículo 1-1 de la Constitución» (FD 5). A juicio del autor de estas líneas, si el recurrente confiaba en la admisión de su escrito (habría que estudiar qué calificativo merece), es que tenía más moral que el alcoyano ${ }^{47}$.

${ }^{44}$ A juicio de Luis E. Delgado no es aplicable este precepto, por ser incompatible con el artículo 22 LOTC que consagra la inviolabilidad de los Magistrados del Tribunal Constitucional. En «La inviolabilidad », cit., pp. 291-293.

45 Como indica Luis E. Delgado, la respuesta dada al recurso de amparo fue razonada, proporcionada y congruente con la pretensión atípica (ibidem, pp. 297-298). Ver también Aguado Renedo, César: «Del intento », cit., p. 11 ss.

46 FD 4. De haber sido así, que no lo era, resultaría de aplicación el artículo 23.1 LOTC por parte del Pleno del Tribunal Constitucional (Delgado del Rincón, Luis E: «Inviolabilidad...», cit., p. 303).

47 Expresión que alude, al parecer, al espíritu de un equipo de fútbol (Ver bttp://www.abc. es/20121031/deportes-futbollabci-leyenda-moral-alcoyano-201210301643.html). Además, las injustificables invectivas del recurrente contra el Tribunal Constitucional permiten constatar «la falta de creencia del demandante en un Estado social y Democrático de Derecho, en uno de sus valores, la justicia y en una de sus instituciones clave, el Tribunal Constitucional» (Delgado del Rincón, Luis E: «Inviolabilidad », cit., p. 304). Y, además, y por si fuera poco, dado que «las pretensiones del recurrentes resultaban insostenibles», resulta imposible que la resolución del Tribunal Constitucional, con independencia de su contenido, haya podido provocar daño alguno [ver Díez-Picazo, 
No sorprenderá al amable lector de estas líneas que tras una visión tan deformada de la actuación de los Magistrados del Tribunal Constitucional y de la angelical confianza del recurrente en el Estado y la Justicia se establezca una clara vinculación (clara e incuestionable, ex FD 6) entre aquélla y el daño causado. Se impone a cada Magistrado del Tribunal Constitucional el pago de una indemnización de quinientos euros que deberán revertirse al original recurrente que un día acudió a un Tribunal inexistente.

Que la resolución dictada por el Tribunal Supremo era disparatada resulta indudable ${ }^{48}$. Y no se puede alegar desconocimiento, puesto que la misma se acompañaba de un Voto Particular, suscrito por el Magistrado Marín Castán ${ }^{49}$. Éste recuerda que la demanda del Letrado Mazón debe ser depurada «de su carga retórica en lo que constituye toda una descalificación del Tribunal Constitucional en términos tan peyorativos y vejatorios que resultan inconciliables con el equilibrio y la mesura $»^{50}$, afirmación ésta poco conciliable con su inusitada fe en la justicia. El Magistrado también señala que la demanda de amparo interpuesta era «radicalmente inadmisible», puesto que se espera algo imposible (una suerte de preiniciativa legislativa) de nadie (puesto que se pide, previamente, la abstención de los Magistrados), y que dicha inadmisión dejaba además expedita la vía ante el Tribunal de Estrasburgo (FD 5). Frente a la singular motivación realizada por la mayoría, estamos ahora en presencia de una fundamentación razonable.

Como ustedes pueden imaginar, la Sentencia de la Sala Primera del Tribunal Supremo produjo estupor y un profundo malestar en el seno del Tribunal Constitucional. El autor de estas líneas, que en aquél momento prestaba allí sus servicios, en calidad de Letrado de adscripción temporal, la entendió como un ataque institucional. No porque tuviera una visión corporativa de la institución, cuyas resoluciones ha criticado en muchas ocasiones, sino porque era evidente que la condena estaba desprovista de cualquier mínima justificación e implicaba, en cierto modo, un golpe de estado judicial ${ }^{51}$. Soy consciente de que esta calificación resulta grave,

Luis M. ${ }^{a}$ : «¿Qué daño ha causado el Tribunal Constitucional?». Derecho y Jueces 15 (2004); Rubio Llorente, Francisco: «El guardián », cit., p. 14 y Aguado Renedo, César: «Del intento », cit., p. 15].

48 Luis E. Delgado recuerda que ha sido considerada de inane contenido (Belloch), estrambótica (Rubio), desproporcionada, desmesurada e incongruente (Rodríguez-Arana), esperpéntica (Gómez de Liaño), opiniones que contrastan con la expresada por Manuel Gómez del Castillo (en «Inviolabilidad », cit., p. 272). Ver, en sentido cercano, Aguado Renedo, César: «Del intento », cit, p. 11.

49 Que comparte Valentín Cortés Domínguez (en «Aproximación», cit., p. 95).

50 Resulta muy conveniente la lectura de las invectivas, resumidas en el apartado segundo del Voto Particular, que no reproducimos por no superar una extensión razonable en páginas en el presente estudio.

${ }^{51}$ Comparto y asumo la expresión vertida por Francisco Rubio Llorente, en «El guardián», cit., p. 14. También se habla en este mismo lugar de que si se consolida la doctrina contenida en 
y que podría haber optado por otras más edulcoradas ${ }^{52}$, pero debemos ser conscientes de que la asunción de la resolución que acaba de resumirse liquida la posición que ocupa el Tribunal Constitucional como órgano constitucional. En efecto, «el Tribunal Constitucional queda seriamente incapacitado para desempeñar su jurisdicción de amparo tal como le viene confiada por la Constitución y su Ley Orgánica» ${ }^{53}$. No resulta extraño que el legislador haya modificado el artículo 4 LOTC a través de la LO 6/2007, de 24 de mayo, incorporando un nuevo apartado segundo en el que se afirma que «las resoluciones del Tribunal Constitucional no podrán ser enjuiciadas por ningún órgano jurisdiccional del Estado».

En todo caso, los Magistrados solamente podían cuestionar la Sentencia condenatoria a través de la interposición de un recurso de amparo ${ }^{54}$. Y aquí cabían dos posibilidades. Una resolución inmediata, realizada por los mismos Magistrados que habían sido condenados, o una suspensión de la causa hasta que pudiera ser atendida, en el futuro, por Magistrados no contaminados. Esta última fue la estrategia seguida. Esta desconexión entre los Magistrados condenados y aquéllos otros que, en el futuro, resolverían la demanda de amparo, permitió a los primeros aprobar un Acuerdo el 3 de febrero de $2004^{55}$ en el que advierte de «que la Sala de lo Civil, al enjuiciar la fundamentación dada por el Pleno a una Resolución de inadmisión, pone en serio peligro la función jurisdiccional de amparo invadiendo competencias que sólo al Tribunal Constitucional corresponden» (Punto 1). De ahí que se haya producido una «invasión de las funciones jurisdiccionales constitucionalmente atribuidas a este Tribunal Constitucional»

la Sentencia del Tribunal Supremo estaríamos ante una «ruptura pacífica del orden instaurado por la Constitución».

52 Tres ex-Presidentes del Tribunal Constitucional (Cruz Villalón, Rodríguez-Piñeiro y Bravo-Ferrer y Rodríguez Bereijo) prefieren aludir a «Una crisis constitucional» en el artículo publicado en El País el 26 de febrero de 2004, disponible en http://elpais.com/diario/2004/02/26/ opinion/1077750007_850215.html.

53 Idem.

54 Es cierto que esta iniciativa podría haber sido adoptada por otras instituciones (especialmente, el Defensor del Pueblo o el Ministerio Fiscal). Sobre esta cuestión, vid. Aguado Renedo, César. «Del intento...», cit., pp. 31-32. Y también que su iniciativa serviría para proteger sus derechos, pero también la Institución que había sido injustamente maltratada por el Tribunal Supremo (ibidem, pp. 34-35).

Por cierto, conviene recordar, de la mano de Rafael Mendizábal, que el 17 de febrero de 2004 la Sala de lo Penal del Tribunal Supremo ordena el archivo de la denuncia promovida por la Asociación contra la Injusticia y la Corrupción quince antes en la que imputa un delito de prevaricación a los Magistrados ya condenados, por entenderla inviable (en «La guerra...», cit., p. 529).

55 JUR 2004 20811. Tiene razón Valentín Cortés Domínguez cuando señala que este Acuerdo es discutible por su tenor sobre la falta de responsabilidad (en «Aproximación», cit., p. 95), que luego matiza, como debe ser, la STC 133/2013. 
(punto 2). Se ha producido, así, una «clara extralimitación competencial, y correlativa invasión de nuestras exclusivas competencias y atribuciones constitucionales» (punto 3). A la vista de estas consideraciones se acuerda declarar «que las resoluciones dictadas por el Tribunal Constitucional en los recursos de amparo no pueden ser enjuiciadas por ningún órgano del Poder Judicial dado que sólo a este Tribunal corresponde, conforme a la Constitución y a su Ley Orgánica, resolver tales recursos» y «que el enjuiciamiento de las resoluciones recaídas en recursos de amparo, realizado por vía de la acción de responsabilidad civil, constituye una invasión de la jurisdicción, exclusiva y excluyente, atribuida a este Tribunal Constitucional por la Constitución».

Y el amparo, justo sin ningún género de dudas, llegó. La STC (Pleno) 133/2013 de 5 junio $^{56}$, considera que se ha lesionado el derecho a la tutela judicial efectiva de

56 RTC 2013\133. Ver, en el plano doctrinal, Delgado del Rincón, Luis E: «La responsabilidad civil de los Magistrados del Tribunal Constitucional en tela de juicio». Teoría y Realidad Constitucional 34 (2014), pp. 561 ss. y un apresurado resumen de Francesca Iusi [«Disputa entre la Sala de lo Civil del Tribunal Supremo y el Tribunal Constitucional sobre la cuestión de la responsabilidad civil de los Magistrados del Tribunal constitucional por adoptar una arbitraria inadmisión del recurso de amparo». Civitas Europa 32 (2014), pp. 273-275]. No examinaremos con detalle esta resolución, aunque sería interesante recordar las originales razones que el Letrado Mazón, que comparece en el proceso como parte personada, plantea y que son rechazadas (Delgado del Rincón, Luis E: «La responsabilidad », cit., pp. 574-575).

Puede parecer sorprendente que la Sentencia de amparo se dicte nueve años después de la condena impuesta por la Sala de lo Civil del Tribunal Supremo, pero debe entenderse que, en un momento inicial, todos los Magistrados estaban contaminados por la causa. De ahí que el Presidente del Tribunal acordara, el 29 de marzo de 2004, suspender toda tramitación procesal del recurso de amparo hasta que pudiera formarse una Sección cuyos miembros no fueran, simultáneamente, recurrentes de amparo. La siguiente Presidenta del Tribunal acuerda, el 4 de abril de 2005, designar sustitutos que permitan formar una Sección Cuarta que pueda pronunciarse sobre las abstenciones formuladas y la admisión del amparo. El ATC 290/2005, de 4 de julio, acepta diversas abstenciones formuladas. El Letrado Mazón decide entonces recusar a todos los Magistrados del Tribunal Constitucional, siendo inadmitido su escrito por no tenerse aún por comparecido (providencia de 4 de julio de 2005), decisión confirmada en súplica (Auto 352/2005). Idénticas pretensiones de doña María del Ángel Sanz Amaro fueron rechazadas (providencias de 4 de julio de 2005 y de 19 de octubre de 2005, confirmada en súplica mediante ATC 428/2005, de 13 de diciembre).

Tras la admisión a trámite de la demanda de amparo, mediante providencia de 27 de abril de 2007, se persona José Luis Mazón Costa. Este impugna la admisión a trámite y solicita la tramitación de los anteriores escritos de recusación. Se inadmite el recurso de súplica interpuesto contra la providencia de admisión del recurso de amparo por ser esta irrecurrible (ATC 159/2008, de 19 de junio). También se produjeron problemas para la composición de la Sala Segunda (ver la providencia de 22 de diciembre de 2008, en la que se dejan pendientes las solicitudes de recusación por ser notoria la falta de quorum en el Pleno para un pronunciamiento sobre el particular). Finalmente, el Pleno inadmite las recusaciones interesadas por el letrado en su ATC 40/2011, de 12 de 
los Magistrados del Tribunal Constitucional. Si bien es cierto que los recurrentes también invocaban el derecho a acceso a las funciones y cargos públicos (art. 23.2 $\mathrm{CE}$ ), en su dimensión de derecho al ejercicio de dichos puestos sin perturbaciones ilegítimas, resulta preciso hacer una adaptación de este derecho cuando se trata, como es aquí el caso, de cargos electivos no representativos (FJ 4). Dado que lo que cuestiona es si existían sendos óbices procesales que impedían la admisión de la causa por parte del Tribunal Supremo (el imposible control y revisión de las resoluciones dictadas por el Tribunal Constitucional y la inviolabilidad de los Magistrados por las opiniones vertidas en el ejercicio de sus cargos), el Pleno prefiere examinar la cuestión desde la perspectiva del derecho a la tutela judicial efectiva (art. 24.1 CE) (FJ 4).

Asumida esta perspectiva, resulta preciso examinar la motivación en lo que atañe a la posibilidad de exigir responsabilidad civil a los Magistrados del Tribunal Constitucional y de hacerlo a través del control de sus resoluciones jurisdiccionales. Ninguna duda cabe de que puede exigirse responsabilidad civil de los Magistrados (prevista en el artículo 23.1.7 LOTC). Pero la decisión del Tribunal Supremo es irrazonable porque desconoce una «prohibición constitucional y legal de revisar y controlar el contenido de las resoluciones jurisdiccionales del Tribunal Constitucional por ningún otro órgano del Estado» ${ }^{57}$.

También considera el Pleno que la Sentencia recurrida carece de una motivación constitucionalmente exigible cuando imputa a los Magistrados del Tribunal Constitucional una actuación antijurídica e irrazonable. De un lado, porque parte de un presupuesto fáctico que se manifiesta erróneo (incurriendo en error patente al olvidar que el Pleno entendió que la demanda adolecía de falta de precisión y claridad). De otro porque resulta irrazonable cuando olvida que, dirigida la demanda de amparo a un órgano indeterminado, el Tribunal Constitucional es el encargado de apreciar, de oficio o a instancia de parte, su falta de jurisdicción o competencia (artículo 4.1 LOTC) (FJ 8). Se ha vulnerado, así, también, el derecho a obtener una resolución fundada en Derecho.

Si bien es posible compartir el sentido general del amparo, estamos en presencia de una resolución que debiera haber sido mucho más sencilla en la deli-

abril, al tiempo que admite las abstenciones formuladas por los Magistrados Gay Montalvo y Delgado Barrio.

57 FJ 6. Se parte de la irrecurribilidad de las decisiones jurisdiccionales del Tribunal Constitucional fuera de los supuestos expresamente previstos en la Ley que regula su funcionamiento. La nulidad no debe suponer retroacción de las actuaciones en este supuesto, dado que la interpretación atañe a preceptos contenidos en la referida Ley, sin que quepa otra distinta por parte del juez ordinario (FJ 6). 
mitación de las quejas y breve en su resolución. Es un texto a veces atormentado y que precisa de varias lecturas para comprender cabalmente su compleja estructura y contenido. En todo caso, bien está lo que bien (aunque tarde) acaba.

Aunque parezca surrealista, el Letrado Mazón ha decidido, rizando el rizo, volver a exigir la responsabilidad de los Magistrados del Tribunal Constitucional por la Sentencia que ha amparado a los ex Magistrados del alto Tribunal. Una vez que la Sala de lo Civil dicta Auto el 22 de octubre de 2013 (JUR 2013 361358), para devolver a los Magistrados el dinero en su día pagado y al Letrado Mazón su consiguiente devolución, éste lo recurre, solicitando su suspensión por haber interpuesto dos querellas ante la Sala de lo Penal del Tribunal Supremo (una ya inadmitida en ese momento ${ }^{58}$ ), pretensión desestimada mediante Auto de 25 de abril de 2014 (JUR 2014 158205). Entonces, el incansable Letrado ha presentado una nueva demanda de responsabilidad civil ante la Sala Primera del Tribunal Supremo por considerar que los Magistrados han amparado a las personas que formaron parte de su mismo Tribunal ${ }^{59}$, que ha sido inadmitida de plano, porque, «Si bien este Tribunal goza de competencia para conocer de la demanda de responsabilidad civil por hechos realizados en el ejercicio de su cargo por el presidente y los magistrados del Tribunal Constitucional, conforme al artículo 56.2 LOPJ, en este caso debemos rechazar de plano la demanda porque persigue única y exclusivamente la revisión de una resolución del Tribunal Constitucional, que en la actualidad está vedado por el artículo 4.2 LOTC» (FD 10). La Sala considera, además, «jurídicamente abusiva la demanda» (FD 11).

58 Solamente hemos sido capaces de localizar el ATS (Sala de lo Penal) de 25 de junio de 2014 , disponible en http://supremo.vlex.es/vid/-533084242. La Sala determina que no hay delito de prevaricación por parte de los Magistrados que han evacuado el recurso de amparo porque en él se da una respuesta motivada (concretamente, en el FJ 3) al alegato de la innecesaridad de promover un incidente de nulidad de actuaciones para agotar correctamente la vía judicial. Y, gracias a Luis E. Delgado, sabemos del ATS (Sala de lo Penal) de 10 de febrero de 2014, en el que se inadmite una querella por prevaricación, que se fundamenta en la «concesión arbitraria de un inexistente régimen de impunidad jurisdiccional a los magistrados del Tribunal Constitucional» invocada por el Letrado Mazón, entendiendo la Sala de lo Penal que no se vislumbra ningún ilícito penal en la STC 133/2013 (en «La responsabilidad », cit., p. 584).

59 El demandante entiende que estamos en presencia de un autoamparo, en el que se han dispensado a los recurrentes de una serie de cargas procesales (haber alegado la lesión del 23.2 CE desde el primer momento, haber interpuesto el oportuno incidente de nulidad de actuaciones, pronunciarse sobre cuestiones de legalidad ordinaria, no respetar los hechos de la sentencia impugnada), y por encontrarse contaminado el Tribunal. 


\section{ALGUNAS CONSIDERACIONES CONCLUSIVAS}

Si se comparten las afirmaciones realizadas en líneas anteriores, podría concluirse que los Tribunales ordinarios pueden, cómo no, mostrar su discrepancia intelectual con algunas de las razones expresadas por otros Tribunales a los que se encuentran vinculados. Esta vale tanto para que un Tribunal ordinario discrepe de un criterio jurisprudencial expresado por el Tribunal Supremo como para que éste ponga de manifiesto las debilidades que, con mayor o menor acierto, advierta en la jurisprudencia constitucional.

Lo que un Tribunal ordinario no puede hacer, y el Tribunal Supremo se incluye en esta categoría, es actuar al margen de su función jurisdiccional (porque no tienen competencia para ello), negarse a acatar una doctrina constitucional (por más desafortunada que ésta pueda ser) o enjuiciar a los Magistrados del alto Tribunal por las resoluciones que emanen de éste.

Podría pensarse que esta forma de enfocar las cosas confiere un gran poder al Tribunal Constitucional, pero resulta evidente que también pesa sobre esta institución una alta dosis de responsabilidad. Una responsabilidad que no siempre ha manejado de forma juiciosa, lo que se ha traducido en serias críticas a su labor y en algunas condenas impuestas al Estado español por parte del Tribunal Europeo de Derechos Humanos.

La pregunta que podría formularse ahora es si se pueden evitar los conflictos entre el Tribunal Constitucional y el Tribunal Supremo ${ }^{60}$. Y nuestra idea es realizar algunas consideraciones sobre esta cuestión, adelantando ya que las discrepancias

${ }^{60}$ Es, obviamente, una pregunta retórica, si pensamos en la inevitable diversidad de criterios jurisdiccionales. No vamos a examinar la jurisprudencia posterior en detalle, como sí hace Rosario Serra Cristóbal (en «Nuevos », cit., pp. 387 ss.), pero sí queremos recordar, de dicho relato, que el Tribunal Constitucional ha seguido controlando aquellas inadmisiones en casación que ha considerado lesivas de los derechos fundamentales de los recurrentes (ver, por ejemplo, las SSTC 161/2008, 100/2009 y 35/2011, recogidas en la p. 389). Tampoco nos detendremos en el análisis de la STS (Sala Tercera) de 26 de noviembre de 2009, en la que se establece la eventual responsabilidad del Tribunal Constitucional por incurrir en dilaciones indebidas en la resolución de una recusación presentada en un recurso de amparo, aunque sea discutible la asimilación del Tribunal Constitucional a una Administración Pública a estos efectos (vid el Voto Particular del Magistrado Díez-Picazo Giménez). Este asunto presenta una naturaleza bien distinta a los tratados en este trabajo, y ha perdido su inicial interés con el vigente artículo 139.5 de la Ley 30/1992, de 26 de noviembre, de Régimen Jurídico de las Administraciones Públicas y del Procedimiento Administrativo Común, aunque pueda profundizarse en el mismo gracias a César Aguado Renedo [en «La responsabilidad patrimonial del Tribunal Constitucional y el Tribunal Supremo». Revista española de Derecho Constitucional 90 (2010), pp. 335 ss.] y a Ángel L. Sanz Pérez [«¿Enjuicia el Tribunal Supremo al Constitucional? Revista Aranzadi Doctrinal 1 (2010)], que asumen un enfoque crítico con la citada resolución judicial. 
jurídicas entre ambas jurisdicciones son, en cierta medida, inevitables. No se trata, tanto, de negar su existencia como de delimitar sus razonables cauces de expresión.

Es verdad que un caso como el vivido resulta hoy imposible, a la vista del tenor expreso del vigente artículo 4.2 LOTC, que impide cualquier control jurisdiccional sobre las resoluciones del Tribunal Constitucional, y con la desaparición de la exigencia de responsabilidad civil en la Ley Orgánica del Poder Judicial ${ }^{61}$.

Pues bien, nos parece imposible, de entrada, tratar de delimitar formalmente las materias sobre las que pueden pronunciarse el Tribunal Supremo y el Tribunal Constitucional ${ }^{62}$. No existen, en puridad, materias reguladas por la legalidad ordinaria que no puedan ser interpretadas por el Tribunal Constitucional si entiende que las mismas se ven afectadas, influenciadas o delimitadas por normas constitucionales, ya que «ni la jurisdicción ordinaria puede, al interpretar y aplicar la Ley, olvidar la existencia de la Constitución, ni puede prescindir la jurisdicción constitucional del análisis crítico de la aplicación que la jurisdicción ordinaria hace de la Ley cuando tal análisis es necesario para determinar si se ha vulnerado o no alguno de los derechos fundamentales o libertades públicas cuya salvaguardia le esté encomendada» ${ }^{63}$. Aunque son muchas las voces que defienden la necesidad de deslindar la actuación de ambos Tribunales ${ }^{64}$, su empeño es más quimérico que real porque, «aunque el Tribunal Supremo sea el tribunal superior de la interpretación «legal» de la ley, el Tribunal Constitucional es el tribunal superior de la interpretación «constitucional» de la ley» ${ }^{65}$.

Tampoco resuelve el problema, con toda seguridad, que se pretenda reformar el amparo (ya sea objetivándolo, como finalmente se ha hecho en la citada LO

${ }^{61}$ Estas reformas traen causa de las LLOO 6/2007, de 24 de mayo, y 7/2015, de 21 de julio. Rosario Serra Cristóbal considera que las principales novedades incluidas en la primera (la nueva configuración del incidente de nulidad de actuaciones y el nuevo requisito de la especial trascendencia constitucional) pueden servir para mejorar las relaciones entre el Tribunal Supremo y el Tribunal Constitucional (en «Nuevos », cit., pp. 382 ss.).

${ }^{62}$ Como ha afirmado Cándido Conde-Pumpido Tourón «es imposible trazar una frontera entre constitucionalidad y legalidad ordinaria», ya que «el ordenamiento jurídico es un sistema y no una mera yuxtaposición de normas» (en «El Tribunal Supremo y los derechos constitucionales». En Trillo Torres, Ramón; Bacigalupo, Enrique y Lucas Murillo de la Cueva, Pablo (coords): El Tribunal..., cit., p. 218). Ver también Tajadura Tejada, Javier.: «La posición constitucional del Tribunal Supremo». Boletín de la Facultad de Derecho 25 (2004), p. 80 y Aragón Reyes, Manuel: «Problemas», cit., pp. 604-605.

63 STC (Sala Segunda) 50/1984/3, de 5 de abril, citado por Rosario Serra Cristóbal en «Nuevos ", cit., p. 395.

${ }^{64}$ Nos remitimos, en este punto, a la extensa nota a pie de página 78 del estudio de DelgaDO DEL RINCÓN, Luis E: «Inviolabilidad», cit., p. 310.

65 Aragón Reyes, Manuel: «Relaciones», cit., p. 177. 


\section{$7 / 2015$, de 21 de julio ${ }^{66}$, ya sea reduciendo su alcance ${ }^{67}$ o suprimiéndolo $\left.{ }^{68}\right)$, puesto que, como es bien sabido, un altísimo porcentaje del control de amparo}

${ }^{66}$ Cfr. Aguado Renedo, César: «Del intento », cit., p. 38; Conde-Pumpido Tourón, Cándido: «El Tribunal », cit., p. 221 y CARrillo, Marc: «Notas sobre la articulación entre la jurisdicción ordinaria y el recurso de amparo». En Trillo Torres, Ramón; BACIGALuPo, Enrique y LuCas Murillo de la Cueva, Pablo (coords): El Tribunal..., cit., p. 253 (sobre la mayor exigencia en la admisión del amparo).

${ }^{67}$ Delgado Del Rincón, Luis E: «Inviolabilidad », cit., pp. 311-312. Vicente Gimeno Sendra recuerda la propuesta de Pascual Sala de que el Tribunal Constitucional no pudiera pronunciarse sobre el principio de igualdad en la aplicación de la Ley, dejando esta cuestión al Tribunal Supremo (en «De nuevo», cit., p. 111). O que todas las demandas de amparo vinculadas con el derecho a la tutela judicial efectiva sean residenciadas, previamente, en una Sala del Tribunal Superior de Justicia o en el Pleno de la Sala del Tribunal Supremo (idea incluida en la «Propuesta de reforma del Tribunal Supremo en atención a sus funciones constitucionales», incluida en $\mathrm{Del}$ modo de arreglar la justicia. Tribunal Supremo. Madrid, 2002 y respaldada por Candido CondePumpido Tourón en «El Tribunal», cit., p. 221, y que es rechazada por el profesor Aragón Reyes porque, entre otras razones, «es justamente la vía que puede garantizar la vinculación de los jueces y tribunales a la doctrina constitucional», en «Problemas...», cit., p. 605). O que, con carácter general, no quepa recurso de amparo frente a resoluciones del Tribunal Supremo (Conde-PumPIDo Tourón, Cándido: «El Tribunal», cit., p. 221 y MuÑoz Campos, Juan: «Recurso», cit., p. 1242). En el mismo sentido se pronuncia Enrique Bustos Pueche, si bien excepciona de lo anterior las relacionadas con el derecho de acceso a la justicia o al recurso (en «Planteamiento...», cit., p. 5). En estas tesis se parte de una premisa que ha verbalizado Giuseppe Campanelli, y es que mientras que la cuestión de inconstitucionalidad presupone la cooperación de los jueces ordinarios con el Tribunal Constitucional, el recurso de amparo es un mecanismo de control sobre las resoluciones judiciales (en «I rapporti...», cit., p. 285), especialmente en la vía prevista en el art. 44 LOTC (ibidem, pp. 266 ss.), debiendo recordar además que el Tribunal Constitucional se ha permitido en ocasiones revisar los hechos (STC 7/1993/5, de 18 de enero), contradiciendo el tenor literal empleado en el artículo 44.1.b LOTC, cosa que no puede hacer el Tribunal Supremo en casación (ibidem, p. 275). Ver, también, MendizÁBAl AlLENDE, Rafael: «La guerra...», cit., p. 535 y los deseos expresados por Juan José González Rivas en «El recurso de amparo y su inserción en las relaciones entre el Tribunal Constitucional y el Tribunal Supremo». Revista General de Legislación y Jurisprudencia 3 (2000), pp. 317-319 y Álvarez Conde, Enrique: «Algunas...», cit., pp. 1347 ss., que incorpora propuestas de reforma del incidente de nulidad de actuaciones (que se ha aprobado muchos años más tarde, y que es vista positivamente por Manuel Aragón Reyes — «Problemas», cit., pp. 605-606-) y de procedimientos de unificación de doctrina.

68 Alessandro Pizzorusso considera que la misma existencia del recurso de amparo «determina desajustes en el ordenamiento constitucional español, uno de los cuales sin duda es la anómala relación que se establece entre el Tribunal Constitucional y el Tribunal Supremo» [en «La posición constitucional del Tribunal Supremo». En Trillo Torres, Ramón; Bacigalupo, Enrique y Lucas Murillo de la Cueva, Pablo (coords): El Tribunal..., cit., p. 39]. Esta peculiaridad diferencia el caso español del italiano (descrito en la p. 40). Javier Aparicio Gallego ha propuesto la eliminación del amparo constitucional (en «Reflexiones sobre la posición constitucional del Tribunal Supremo», ibidem, p. 137), y en contra se han mostrado Enrique Álvarez Conde (en «Algunas...», cit., p. 1344) y Francisco Marín Castán [en «El Tribunal Supremo en el ordenamiento 
siguen teniendo vinculación con los derechos recogidos en los apartados primero y segundo del artículo 24 de la Constitución ${ }^{69}$ y porque casi todos los derechos precisan una mayor o menor configuración legal ${ }^{70}$.

Buena prueba de esta consideración es que la reforma del amparo constitucional no ha impedido la existencia de nuevos supuestos donde se ha mostrado una discrepancia entre la jurisprudencia del Tribunal Constitucional y la del Tribunal Supremo. En páginas anteriores (apartado 2.2 in fine) se ha hecho referencia a la STC 32/2013, de 11 de febrero, y en la nota 58 se ha aludido a las SSTC 161/2008, 100/2009 y 35/2011.

Sí que resultaría preciso, a mi juicio, apelar a la constante prudencia del Tribunal Constitucional ${ }^{71}$. Prudencia que no debe coartar su facultad de defender e interpretar la Constitución, así como los derechos fundamentales que justifican todo nuestro modelo de convivencia, pero sí servir para no alterar construcciones jurisprudenciales mantenidas durante décadas sin que nadie antes se hubiera percatado de su naturaleza manifiestamente inconstitucional ${ }^{72}$. Expresado en acertadas palabras de Rafael Mendizábal: «Pues bien, dada su posición constitucional prevalente, al Tribunal Constitucional le corresponde, precisamente por ello, tomar conciencia no sólo de su poder sino de sus limitaciones. Sólo una exigente actitud de autocontención evitará intromisiones y, con ello, conflictos. En caso contrario no sería atendible su queja porque entraran en juego los «frenos y contrapesos» propios del sistema democrático, alguno de los cuales -res-

constitucional». En Trillo Torres, Ramón; Bacigalupo, Enrique y Lucas Murillo de la Cueva, Pablo (coords): El Tribunal..., cit., p. 229 ss.].

69 En http://www.tribunalconstitucional.es/es/tribunal/estadisticas/Paginas/Estadisticas2014.aspx (cuadro 13) se pueden consultar los reveladores datos referidos al año 2014.

70 Ver Gimeno SEndRa, Vicente: «De nuevo...», cit., p. 105, que alude a los derechos fundamentales de configuración legal. Ver, con carácter general, Jiménez CAMPO, Javier: Derechos fundamentales: concepto y garantía. Trotta. Madrid, 1999, que explica el relevante papel de la Ley en la definición, concreción y desarrollo de los derechos fundamentales.

71 Discrepa de esta solución Conde-Pumpido Tourón, Cándido: «El Tribunal », cit., p. 218, con apoyo del citado discurso del Presidente del Supremo, Sr. Sala, en la apertura del año judicial de 1994. Rafael Mendizábal opina, por otra parte, que el activismo del Tribunal Constitucional de los primeros años deja paso al self-restraint a partir de 1992, aunque dicha tendencia sufra altibajos (en «La guerra...», cit., p. 511). Y Enrique Álvarez Conde también aconseja esta elemental prudencia (en «Algunas...», cit., p. 1351). Manuel Aragón la extiende a la jurisdicción ordinaria, que deberá plantear una cuestión de inconstitucionalidad cuando dude de la constitucionalidad de un precepto normativo con fuerza de Ley (en «Problemas », cit., p. 606).

${ }^{72}$ Manuel Aragón Reyes va más lejos, apostando por la aplicación del principio in dubio, que debería conducir a que el Tribunal Constitucional únicamente anule la interpretación de la Ley realizada por el Tribunal Supremo cuando ésta sea manifiestamente inconstitucional (en «Problemas ", cit., p. 605). 
ponsabilidad civil e incluso penal- están en manos del Tribunal Supremo. El blindaje frente a ellos no sería sano para la consolidación y perfeccionamiento del Estado de Derecho, sino al contrario» ${ }^{73}$.

También resulta conveniente que el Tribunal Constitucional disponga de la última palabra, cuando estima que se ha producido una vulneración de un derecho procesal (en sentido amplio) por parte de los Tribunales ordinarios ${ }^{74}$. Esta actuación servirá para evidenciar la existencia de un principio de lealtad institucional. Es cierto que hay motivos que pueden explicar que, en ocasiones, se haya optado por anular la resolución judicial impugnada en amparo y confirmar la firmeza de otra (dictada en instancia o apelación). Uno, bastante evidente, es no alargar más una causa en la que, no lo olvidemos, hay un recurrente que lleva casi siempre años esperando obtener el amparo solicitado. Otro, presente en algunos de los casos examinados en este trabajo, que es evitar que el Tribunal autor de la resolución judicial cuestionada pueda obstaculizar la concesión del amparo.

Resulta claro que esta última justificación debería ser desterrada. Y ello no solamente porque de esta forma se consagraría un anormal funcionamiento del poder judicial en nuestro país, sino también, y sobre todo, porque de esta forma el Tribunal Constitucional podría recibir un feedback de su labor. Una retroalimentación en la que ya no se cuestionaría su autoridad, sino sus argumentos. Es probable que esta sana crítica, como la proveniente del ámbito doctrinal, pudiera contribuir a mejorar la calidad de las resoluciones del Alto Tribunal, contribuyendo, así, a mejorar nuestro actual Estado constitucional.

73 En «La guerra...», cit., p. 534. Debe matizarse que hoy ya no es exigible la responsabilidad civil ante la Sala de lo Civil del Tribunal Supremo, aunque siga vigente la responsabilidad extracontractual prevista en el artículo 1902 CC.

${ }^{74}$ Juan Antonio Xiol Ríos denomina, gráficamente, a estas situaciones como de cortocircuito procesal en «La posición...», cit., pp. 98 ss. Ver, también, CAMPANELLI, Giuseppe: «I rapporti...», cit., pp. 275 ss. Y debe de indicarse que, aunque no sólo se ha visto afectada por ellas el Tribunal Supremo (vid la STC 170/1994), resulta grave aceptar que la Sentencia anulada presenta un problema relacionado con la tutela judicial efectiva y negarle la posibilidad de repararlo por sí mismo. Aunque esto es lo ocurrido con algunas de las Sentencias contempladas en estas líneas, es forzoso admitir que en algunas circunstancias (como son las concurrente en el caso Isabel Preysler II o en el amparo de los ex-Magistrados del Tribunal Constitucional) era la solución más razonable si se quería solventar, de una vez por todas, la rebelión protagonizada por la Sala Primera del Tribunal Supremo. Dicho con otras palabras, aunque tal comportamiento sea discutible en el plano dogmático e institucional, devolver la causa al Tribunal ordinario hubiera supuesto un alargamiento de la vía judicial (con perjuicio de los recurrentes) y del conflicto procesal (con perjuicio para la propia pervivencia del modelo constitucional que nos hemos dado). 
Title:

The taut relationship between Supreme Court and Constitutional Court and the limits of the (legitimate) disagreements within.

\title{
Table of Contents:
}

1. Previous considerations on constitutional precedent and its critique. 2. Arguable behaviours. 2.1 The Judiciary should talk through their decisions. 2.2 The Judiciary should respect the constitutional precedent. 2.3 A single Court could not control the jurisdictional activity of the Constitutional Judges. 3. Final considerations.

\section{Resumen:}

Como es sabido, el Tribunal Supremo ha mostrado en algunas ocasiones una profunda discrepancia con resoluciones emanadas del Tribunal Constitucional. En este trabajo se defiende la crítica leal de los tribunales a la doctrina vinculante de otros que les viene impuesta por nuestro ordenamiento, siempre que se haga en el marco de su actuación jurisdiccional y se acepte su vinculación con dicha doctrina. Se critica, por el contrario, la adopción de medidas ajenas a dicha función (pedir el amparo del Rey, adoptar acuerdos plenarios de dudosa naturaleza jurídica), la negativa a asumir esa jurisprudencia y el intento de controlar la actuación jurisdiccional de los Magistrados del Tribunal Constitucional. Se concluye afirmando que dicha tensión es, en cierta medida, inevitable, y que debe apelarse a la prudencia del Tribunal Constitucional en su actuación y a la lealtad institucional de los tribunales ordinarios en su labor.

\begin{abstract}
:
As it is known, the Supreme Court has sometimes showed up a deep disagreement with some of the constitutional precedent. In one hand, this paper defends the Judiciary trustworthy criticism with them, assuming the mandatory links that the Law establishes between rulings. On the other hand, it is not reliable other actions that have little to do with the jurisdictional function (asking for Royal assessment, ruling some uncertain regulations), also meaning refusing to accept that legal body, or/and trying to control the jurisdictional activity of the Constitutional Judges. The conclusion is that some sort of strain is unavoidable, calling to the care and prudence of the Constitutional Court rulings, also to the institutional loyalty of the Judiciary.
\end{abstract}


Palabras clave:

Tribunal Constitucional - Tribunal Supremo - Recurso de amparo Interpretación constitucional - Legalidad ordinaria.

Key words:

Constitutional Court - Supreme Court - Appeal for Constitutional Right's Legal Protection- Constitutional Interpretation - Regular Law. 
